\title{
Lasting Effects of Developmental Dexamethasone Treatment on Neural Cell Number and Size, Synaptic Activity, and Cell Signaling: Critical Periods of Vulnerability, Dose-Effect Relationships, Regional Targets, and Sex Selectivity
}

\author{
Marisa L Kreider', Charlotte A Tate', Mandy M Cousins', Colleen A Oliver', Frederic J Seidler' and \\ Theodore A Slotkin*,I \\ 'Department of Pharmacology and Cancer Biology, Duke University Medical Center, Durham, NC, USA
}

\begin{abstract}
Glucocorticoids administered to prevent respiratory distress in preterm infants are associated with neurodevelopmental disorders. To evaluate the long-term effects on forebrain development, we treated developing rats with dexamethasone (Dex) at 0.05, 0.2, or 0.8 mg/ $\mathrm{kg}$, doses below or spanning the range in clinical use, testing the effects of administration during three different stages: gestational days 17-19, postnatal days 1-3, or postnatal days 7-9. In adulthood, we assessed biomarkers of neural cell number and size, cholinergic presynaptic activity, neurotransmitter receptor expression, and synaptic signaling mediated through adenylyl cyclase (AC), in the cerebral cortex, hippocampus, and striatum. Even at doses that were devoid of lasting effects on somatic growth, Dex elicited deficits in the number and size of neural cells, with the largest effect in the cerebral cortex. Indices of cholinergic synaptic function (choline acetyltransferase, hemicholinium-3 binding) indicated substantial hyperactivity in males, especially in the hippocampus, effectively eliminating the normal sex differences for these parameters. However, the largest effects were seen for cerebrocortical cell signaling mediated by AC, where Dex treatment markedly elevated overall activity while obtunding the function of G-protein-coupled catecholaminergic or cholinergic receptors that stimulate or inhibit AC; uncoupling was noted despite receptor upregulation. Again, the effects on signaling were larger in males and offset the normal sex differences in AC. These results indicate that, during critical developmental periods, Dex administration evokes lasting alterations in neural cell numbers and synaptic function in forebrain regions, even at doses below those used in preterm infants.
\end{abstract}

Neuropsychopharmacology (2006) 3 I, 12-35. doi: I 0. I038/sj.npp. I 300783; published online 25 May 2005

Keywords: acetylcholine systems; adenylyl cyclase signaling; antenatal glucocorticoids; brain development; dexamethasone; noradrenergic systems; preterm delivery

\section{INTRODUCTION}

Preterm delivery is a leading cause of neonatal morbidity and mortality, and glucocorticoids are typically administered to prevent neonatal respiratory distress, a major factor contributing to adverse outcomes (Gilstrap et al, 1994). Glucocorticoids, notably dexamethasone (Dex) and betamethasone, are currently used in one in every 10 US pregnancies, thus encompassing hundreds of thousands of infants born each year (Matthews et al, 2002). Despite their

*Correspondence: Dr TA Slotkin, Department of Pharmacology and Cancer Biology, Duke University Medical Center, Box 3813 DUMC, Room CI62, LSRC Building, Research Drive, Durham, NC 27710, USA, Tel: 919 68I 80I5, Fax: 919684 8197, E-mail: t.slotkin@duke.edu Received 14 March 2005; revised 19 April 2005; accepted 25 April 2005

Online publication: 25 April 2005 at http://www.acnp.org/citations/ Npp042505050 I 79/default.pdf propensity to cause growth impairment, multiple glucocorticoid courses have become common (Crowther and Harding, 2003; Dammann and Matthews, 2001), and are increasingly suspected to contribute to subsequent metabolic, cardiovascular, and behavioral anomalies (Barrington, 2001; Seckl, 2001; Shinwell et al, 2000; Trautman et al, 1995; Yeh et al, 2004).

Many animal studies of glucocorticoid effects on neurodevelopment involve doses sufficient to produce persistent stunting of somatic growth, outright cerebral atrophy, and endocrine disruption (Bohn, 1984; Fuxe et al, 1994, 1996; Gilad et al, 1998; Gould et al, 1997; Maccari et al, 2003; Matthews, 2000; Matthews et al, 2002; McEwen, 1992; Meaney et al, 1996; Weinstock, 2001; Welberg and Seckl, 2001). This leaves major uncertainties as to specific glucocorticoid effects at or below the threshold for typical therapeutic use, or for use within specific phases of neurodevelopment most appropriate to exposure of preterm 
infants. We recently found that Dex treatment, even at doses that do not compromise long-term somatic growth, nevertheless disrupts cell acquisition, indices of neuritic outgrowth, synaptic activity, and cell signaling involved in trophic regulation of forebrain development (Kreider et al, 2005a). These effects were associated with long-term changes in motor and social activities, and cognitive performance (Kamphuis et al, 2003, 2004; Kreider et al, $2005 \mathrm{~b})$, resembling those seen in models of prenatal stress (Bowman et al, 2004; Dean et al, 2001; Felszeghy et al, 2000; Muneoka et al, 1997). The vulnerability of the forebrain to developmental disruption by Dex represents the targeting of peak periods of neuronal cell replication and differentiation in the perinatal period (Bell et al, 1986; Rodier, 1988), combined with high expression of glucocorticoid receptors (Speirs et al, 2004) and an inability of the developing organism to limit glucocorticoid effects by downregulating the receptors (Ghosh et al, 2000).

In the current study, we evaluated the long-term effects of Dex administered to rats during defined perinatal periods corresponding to phases of human neurodevelopment in the second to early third trimester, the period in which glucocorticoids are most likely to be used in preterm infants (Dobbing and Sands, 1979; Gilstrap et al, 1994; Kreider et al, 2005a; Rodier, 1988): gestational days (GD) 17-19, postnatal days (PN) 1-3 and PN7-9. For each of these regimens, we explored the effects of doses well below $(0.05 \mathrm{mg} / \mathrm{kg})$ or within the recommended therapeutic range $(0.2$ or $0.8 \mathrm{mg} /$ $\mathrm{kg}$ ). Our strategy was based on our earlier study, which detailed the immediate impact of these treatments on forebrain development (Kreider et al, 2005a), except that, for the current evaluations in adulthood (PN75), we separated the forebrain into its three major constituent regions, the cerebral cortex, hippocampus, and striatum. In addition, given our earlier observation (Kreider et al, $2005 \mathrm{~b})$ that the GD17-19 regimen, like prenatal stress (Bowman et al, 2004; Gerardin et al, 2005; Rieger et al, 2004), obtunds the normal sex differences in a number of behaviors, we contrasted the long-term effects in males and females. First, we compared the lasting effects on somatic growth to those on brain region weights and on neural cell packing density and total cell number in each region, by measurements of DNA and cell protein fractions. Since each neural cell contains a single nucleus (Winick and Noble, 1965), the DNA concentration (DNA per unit tissue weight) assesses the cell packing density, whereas the DNA content (DNA per region) gives an index of the total number of cells (Bell et al, 1987; Slotkin et al, 1984; Winick and Noble, 1965). Neuronal growth and the accompanying cell enlargement necessitate a rise in the ratio of total protein/ DNA (Qiao et al, 2003, 2004; Slotkin et al, 2005) and the formation of neuritic projections elicits a corresponding rise in the contribution of membrane proteins relative to other cell proteins (membrane/total protein ratio). Accordingly, we assessed these indices as well.

We then focused on the effects directed toward two specific neurotransmitter systems, acetylcholine and norepinephrine, both of which are likely targets for developmental effects of glucocorticoids (Hu et al, 1996; Kreider et al, 2005a, b; Muneoka et al, 1997; Reznikov et al, 2004; Shi et al, 1998; Slotkin et al, 1982; Zahalka et al, 1993b). Acetylcholine systems were evaluated with assays of choline acetyltransferase (ChAT) activity and the binding of $\left[{ }^{3} \mathrm{H}\right]$ hemicholinium-3 (HC3) to the high-affinity presynaptic choline transporter. ChAT, the enzyme responsible for acetylcholine biosynthesis, is a constitutive marker for cholinergic nerve terminals and serves as an archetypal measure of cholinergic innervation, but its activity does not respond to changes in impulse flow. Accordingly, ChAT increases in parallel with the number of cholinergic nerve terminals but does not change in response to stimuli that alter cholinergic neuronal activity (Aubert et al, 1996; Happe and Murrin, 1992; Navarro et al, 1989; Slotkin et al, 1990; Zahalka et al, 1992, 1993a). In contrast, high-affinity choline uptake, as assessed with the binding of HC3 to the presynaptic high-affinity choline transporter, is responsive to neuronal activity (Klemm and Kuhar, 1979; Simon et al, 1976) and the comparative changes in ChAT and HC3 binding or transporter function permit distinction between effects on synaptic outgrowth as distinct from synaptic activity (Aubert et al, 1996; Happe and Murrin, 1992; Navarro et al, 1989; Slotkin et al, 1990; Zahalka et al, 1992, 1993a). We also characterized three neurotransmitter receptor-binding sites, the $\beta$-adrenoceptor ( $\beta \mathrm{AR})$, the $\alpha_{2}$ adrenoceptor $\left(\alpha_{2} \mathrm{AR}\right)$, and the $\mathrm{m}_{2}$-muscarinic acetylcholine receptor $\left(\mathrm{m}_{2} \mathrm{AChR}\right)$, along with their abilities to influence cell signaling mediated by adenylyl cyclase (AC). In addition to assessing basal AC activity, we evaluated the enzymatic response mediated by the three neurotransmitter receptors as well as the response to dopaminergic stimulation, and compared the effects on receptor coupling to those on total AC activity evaluated with direct enzymatic stimulants, $\mathrm{Mn}^{2+}$ and forskolin (Limbird and Macmillan, 1981; Seamon and Daly, 1986; Zeiders et al, 1999b).

Finally, we compared several of the indices for Dex effects on forebrain regions to those in the cerebellum, a region in which neurogenesis occurs much later than in the forebrain (Bell et al, 1986; Rodier, 1988) and for which high doses of Dex elicit outright stunting (Bohn, 1984). In this region, we performed a longitudinal assessment from birth to adulthood with one treatment regimen (GD17-19), in order to evaluate the possibility that neurochemical abnormalities may be attenuated in adulthood as compared to earlier stages of neurodevelopment.

\section{METHODS}

\section{Animal Treatments}

All studies were performed in accordance with the Declaration of Helsinki and with the Guide for the Care and Use of Laboratory Animals as adopted and promulgated by the National Institutes of Health. Timed-pregnant Sprague-Dawley rats were housed individually and given free access to food and water. For studies of gestational Dex exposure, dams received daily subcutaneous injections of Dex phosphate $(0.05,0.2$, or $0.8 \mathrm{mg} / \mathrm{kg})$ on GD17-19, whereas controls received equivalent volumes $(1 \mathrm{ml} / \mathrm{kg})$ of isotonic saline vehicle. On the day after birth, all pups were randomized within their respective treatment groups and redistributed to the nursing dams, maintaining a litter size of 10 to ensure standard nutrition. Randomization was repeated every 3-4 days and in addition, dams were rotated among litters to obviate any differences in maternal 
caretaking. Cross-fostering of Dex-exposed pups to control dams does not alter its developmental effects nor does fostering of normal pups by Dex-treated dams produce apparent treatment effects in controls (Nyirenda et al, 2001). For studies of the effects of postnatal Dex treatment, pups were given $0,0.05,0.2$, or $0.8 \mathrm{mg} / \mathrm{kg}$ on PN1-3 or PN79) and the same randomization procedures were followed. On PN75, animals were decapitated, the cerebellum was removed and the forebrain was separated from the brainstem by a cut rostral to the thalamus, after which it was dissected into its constituent regions, the cerebral cortex, hippocampus, and striatum. Brain regions were frozen in liquid nitrogen and stored at $-45^{\circ} \mathrm{C}$.

Each treatment group consisted of six males and six females, with each animal derived from a different litter. In an additional set of studies, cerebellar development was assessed longitudinally in animals treated with Dex on GD17-19 over the course from birth through adulthood, assessing three males and three females per treatment group at each age, except on PN75, where six animals of each sex were used. As in the forebrain studies, within each treatment group at a given age, each animal was derived from a different litter.

\section{Biomarkers of Neural Cell Number and Size}

Tissues were thawed in 19 volumes of ice-cold $10 \mathrm{mM}$ sodium-potassium phosphate buffer $(\mathrm{pH} 7.4)$ and homogenized with a Polytron (Brinkmann Instruments, Westbury, NY). DNA was assessed with a modified (Trauth et al, 2000) fluorescent dye-binding method (Labarca and Piagen, 1980). Aliquots were diluted in $50 \mathrm{mM}$ sodium phosphate, $2 \mathrm{M} \mathrm{NaCl}, 2 \mathrm{mM}$ EDTA ( $\mathrm{pH} 7.4$ ) and sonicated briefly (Virsonic Cell Disrupter, Virtis, Gardiner, NY). Hoechst 33258 was added to a final concentration of $1 \mu \mathrm{g} / \mathrm{ml}$. Samples were then read in a spectrofluorometer using an excitation wavelength of $356 \mathrm{~nm}$ and an emission wavelength of $458 \mathrm{~nm}$, and were quantitated using standards of purified DNA. The total concentration of tissue proteins was assayed from the original homogenate spectrophotometrically with bicinchoninic acid (Smith et al, 1985); in addition, we assessed the concentration of membrane proteins from the membrane preparations used for radioligand binding, as described below. For calculation of the ratio of membrane/total protein, the membrane protein value was averaged across the different membrane preparations.

\section{Cholinergic Presynaptic Biomarkers}

Aliquots of the original tissue homogenate were assayed in duplicate for ChAT using established procedures (Lau et al, 1988; Qiao et al, 2003, 2004). Each tube contained final concentrations of $60 \mathrm{mM}$ sodium phosphate $(\mathrm{pH} 7.9)$, $200 \mathrm{mM} \mathrm{NaCl}, 20 \mathrm{mM}$ choline chloride, $17 \mathrm{mM} \mathrm{MgCl}_{2}$, $1 \mathrm{mM}$ EDTA, $0.2 \%$ Triton $\mathrm{X}-100,0.12 \mathrm{mM}$ physostigmine, $0.6 \mathrm{mg} / \mathrm{ml}$ bovine serum albumin, and $50 \mu \mathrm{M}\left[{ }^{14} \mathrm{C}\right]$ acetylcoenzyme A. Blanks contained homogenization buffer instead of the tissue homogenate. Samples were preincubated for $15 \mathrm{~min}$ on ice, transferred to a $37^{\circ} \mathrm{C}$ water bath for $30 \mathrm{~min}$, and the reaction was terminated by placing the samples on ice. Labeled acetylcholine was then extracted, counted, and the activity determined relative to tissue protein (Smith et al, 1985). Preliminary determinations established that enzyme activity was linear with time and tissue concentration under these conditions.

For measurements of $\mathrm{HC} 3$ binding, an aliquot of the same tissue homogenate was sedimented at $40000 \mathrm{~g}$ for $15 \mathrm{~min}$ and the supernatant solution was discarded. The membrane pellet was resuspended (Polytron) in the original volume of buffer, resedimented, and the resultant pellet was resuspended using a smooth glass homogenizer fitted with a Teflon pestle, in $10 \mathrm{mM}$ sodium-potassium phosphate buffer (pH 7.4) containing $150 \mathrm{mM} \mathrm{NaCl}$. Radioligand binding was evaluated with $2 \mathrm{nM}\left[{ }^{3} \mathrm{H}\right] \mathrm{HC} 3$ (Vickroy et al, 1984), with incubation for $20 \mathrm{~min}$ at room temperature, followed by rapid vacuum filtration onto glass fiber filters (presoaked for $30 \mathrm{~min}$ with $0.1 \%$ polyethyleneimine in buffer). The nonspecific component was defined as radioligand binding in the presence of an excess concentration of unlabeled $\mathrm{HC} 3(10 \mu \mathrm{M})$ and binding values were expressed relative to membrane protein. Nonspecific binding averaged $60 \%$ in the cerebral cortex and hippocampus, but only $35 \%$ in the striatum.

ChAT and HC3 binding were not assessed in the cerebellum, a region in which cholinergic innervation is sparse.

\section{Neurotransmitter Receptor Binding}

Receptor binding was assessed in aliquots of the same original homogenate in sodium-potassium phosphate buffer as already described for the HC3 binding determinations. After the first sedimentation, we followed two different procedures for subsequent resuspension, washing, resedimentation, and final suspension. For $\beta \mathrm{AR}$ binding, $\alpha_{2} \mathrm{AR}$ binding, and AC activity, the buffer consisted of

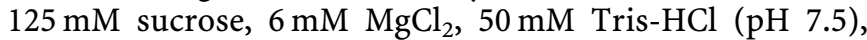
whereas for $\mathrm{m}_{2} \mathrm{AChR}$ binding, the same sodium-phosphate buffer was used as for HC3. To evaluate $\beta \mathrm{AR}$ binding, aliquots of membrane preparation were incubated with $\left[{ }^{125} \mathrm{I}\right]$ iodopindolol (final concentration $67 \mathrm{pM}$ ), in $145 \mathrm{mM}$ $\mathrm{NaCl}, 2 \mathrm{mM} \mathrm{MgCl}, 1 \mathrm{mM} \mathrm{Na}$ ascorbate, $20 \mathrm{mM}$ Tris $(\mathrm{pH}$ 7.5 ), for $20 \mathrm{~min}$ at room temperature in a total volume of $250 \mu$ l. Displacement of nonspecific binding was evaluated with $100 \mu \mathrm{M} d$,l-isoproterenol, comprising $10 \%$ of total binding. For $\alpha_{2} \mathrm{AR}$ binding, the ligand was $2.5 \mathrm{nM}\left[{ }^{3} \mathrm{H}\right] \mathrm{rau}-$ wolscine, which was incubated for $20 \mathrm{~min}$ at room temperature, with membrane preparation and final concentrations of $10 \mathrm{mM} \mathrm{MgCl}_{2}$ and $50 \mathrm{mM}$ Tris ( $\mathrm{pH}$ 7.5). Nonspecific binding was evaluated with $10 \mu \mathrm{M}$ phentolamine, and constituted $20 \%$ of the total. Binding to $\mathrm{m}_{2} \mathrm{AChRs}$ was evaluated with $1 \mathrm{nM}\left[{ }^{3} \mathrm{H}\right] \mathrm{AFDX} 384$, incubated for $60 \mathrm{~min}$ at room temperature in $10 \mathrm{mM}$ sodium phosphate ( $\mathrm{pH} 7.4$ ), and nonspecific binding was evaluated with $1 \mu \mathrm{M}$ atropine; nonspecific binding was $10 \%$. Owing to of the limitations in the amount of tissue available, only selected receptors were assayed in the hippocampus, striatum, and cerebellum.

\section{AC Activity}

AC assessments were conducted by standard techniques published previously (Auman et al, 2000, 2001a; Zeiders 
et al, 1997, 1999a). Briefly, aliquots of the same membrane preparation used for the $\beta \mathrm{AR}$-binding assays were incubated for $10 \mathrm{~min}$ at $30^{\circ} \mathrm{C}$ with final concentrations of $100 \mathrm{mM}$ Tris- $\mathrm{HCl}$ ( $\mathrm{pH}$ 7.4), $10 \mathrm{mM}$ theophylline, $1 \mathrm{mM}$ ATP, $2 \mathrm{mM} \mathrm{MgCl}, 1 \mathrm{mg} / \mathrm{ml}$ bovine serum albumin, and a creatine phosphokinase-ATP-regenerating system consisting of $10 \mathrm{mM}$ sodium phosphocreatine and $8 \mathrm{IU} / \mathrm{ml}$ phosphocreatine kinase, with $10 \mu \mathrm{M}$ GTP in a total volume of $250 \mu \mathrm{l}$. The enzymatic reaction was stopped by placing the samples in a 90- $100^{\circ} \mathrm{C}$ water bath for $5 \mathrm{~min}$, followed by sedimentation at $3000 \mathrm{~g}$ for $15 \mathrm{~min}$, and the supernatant solution was assayed for cyclic AMP using radioimmunoassay kits. Preliminary experiments showed that the enzymatic reaction was linear well beyond the assay period and was linear with membrane protein concentration; concentrations of cofactors were optimal and, in particular, higher concentrations of GTP produced no further augmentation of activity.

AC activity was evaluated in several different ways. First, we measured basal AC activity without addition of any stimulants. Next, we compared the responses of two direct AC stimulants, forskolin $(100 \mu \mathrm{M})$ and $\mathrm{Mn}^{2+}(10 \mathrm{mM})$; these discriminate the effects of $\mathrm{G}_{\mathrm{s}}-\mathrm{AC}$ association, which selectively enhances the forskolin response (Limbird and Macmillan, 1981; Seamon and Daly, 1986), as well as allowing for detection of shifts in the AC isoform (Zeiders et al, 1999b). Finally, we compared the responses to activation of different neurotransmitter receptor stimulants, using $100 \mu \mathrm{M}$ isoproterenol ( $\beta \mathrm{AR}$ agonist), $100 \mu \mathrm{M}$ dopamine (striatum only), $100 \mu \mathrm{M}$ clonidine $\left(\alpha_{2} \mathrm{AR}\right.$ agonist), or $100 \mu \mathrm{M}$ carbachol ( $\mathrm{m}_{2} \mathrm{AChR}$ agonist). As the latter two act in large part on the inhibitory $G$-protein, $G_{i}$, their assessments were conducted in samples that were activated by addition of forskolin (Auman et al, 2001a, b; Garofolo et al, 2002; Slotkin et al, 1991b). These concentrations of each stimulant produce maximal responses, as assessed in earlier studies (Auman et al, 2000, 2001a; Zeiders et al, 1997, 1999a).

\section{Data Analysis}

Data are presented as means and standard errors. Differences between groups were first assessed by a global ANOVA (data log-transformed because of heterogeneous variance), incorporating all factors: treatment regimen, dose, brain region, and sex. This initial test was conducted across related measurements (considered as repeated measures, since they were all derived from the same homogenate) corresponding to each index class: indices of cell number (DNA concentration and content), cell size (total protein/DNA, membrane/total protein), cholinergic presynaptic markers (ChAT, HC3), receptor binding ( $\beta \mathrm{AR}$, $\left.\alpha_{2} \mathrm{AR}, \mathrm{m}_{2} \mathrm{AChR}\right)$, and the multiple AC measures. Depending on the treatment interactions obtained in the global tests, data were then subdivided for lower order ANOVAs, followed where appropriate, by Fisher's Protected Least Significant Difference to establish effects comparing individual groups. Significance for main treatment effects was assumed at $p<0.05$; however, for interactions at $p<0.1$, we also examined whether lower order main effects were detectable after subdivision of the interactive variables (Snedecor and Cochran, 1967). For convenience, some data are presented as the percentage change from control values; however, statistical evaluations were always carried out on the original data. For reference, control values for the forebrain regions are detailed in Table 1, compiled across all three control cohorts (those receiving vehicle injections on GD17-19, PN1-3, or PN7-9); however, the effects of Dex were determined only against the appropriately matched control cohort. Control values for the longitudinal evaluations in the cerebellum are detailed in Table 2.

\section{Materials}

Animals were purchased from Charles River Laboratories, Raleigh, NC. $\left[{ }^{14} \mathrm{C}\right]$ Acetyl-CoA (specific activity $44 \mathrm{mCi} /$ $\mathrm{mmol}$, diluted with unlabeled compound to $6.7 \mathrm{mCi} / \mathrm{mmol}$ ), $\left[{ }^{3} \mathrm{H}\right] \mathrm{HC} 3(161 \mathrm{Ci} / \mathrm{mmol}),\left[{ }^{125} \mathrm{I}\right]$ iodopindolol $(2200 \mathrm{Ci} / \mathrm{mmol})$, $\left[{ }^{3} \mathrm{H}\right]$ rauwolscine $(78 \mathrm{Ci} / \mathrm{mmol})$, and $\left[{ }^{3} \mathrm{H}\right]$ AFDX384 $(133 \mathrm{Ci} /$ mmol) were obtained from PerkinElmer Life Sciences (Boston, MA). Cyclic AMP radioimmunoassay kits were purchased from GE Healthcare (Piscataway, NJ). Sigma Chemical Co. (St. Louis, MO) was the source for all other reagents.

\section{RESULTS}

In forebrain regions of control rats, there were few sex differences in indices of cell number and cell size, but, in contrast, biomarkers of synaptic activity and cell signaling indicated significant distinctions between males and females (Table 1). Females displayed higher ChAT activity and HC3 binding, particularly in the hippocampus. Similarly, AC activities were higher overall in females, particularly in the cerebral cortex. The striatum showed the smallest sex disparities.

Superimposed on the sex differences, the direct AC stimulants, forskolin and $\mathrm{Mn}^{2+}$, evoked massive responses in all regions $(p<0.0001$ for each response), with $7-9$-fold activation in the cerebral cortex and hippocampus, but much larger responses in the striatum (15-fold for $\mathrm{Mn}^{2+}$, more than 40 -fold for forskolin). Additionally, the relative stimulation was significantly higher in females $(p<0.0003$ and $p<0.0001$ for $\mathrm{Mn}^{2+} /$ basal AC and forskolin/basal AC, respectively). The regions also differed substantially $(p<0.0001)$ in their preference for responses to $\mathrm{Mn}^{2+}$ and forskolin, in keeping with disparate catalytic characteristics expected from different AC isoforms and G-protein contributions (Limbird and Macmillan, 1981; Seamon and Daly, 1986; Zeiders et al, 1999b). Forskolin was more effective than $\mathrm{Mn}^{2+}$ in the cerebral cortex and hippocampus but the reverse was true for the striatum.

Catecholamines (isoproterenol in the cerebral cortex and hippocampus, dopamine in the striatum) significantly increased AC activity $(p<0.0001)$, eliciting responses that differed among regions $(p<0.0001)$ but not between sexes. In keeping with the small proportion of total AC activity linked specifically to $\beta \mathrm{ARs}$, the response, assessed as the percent increase over basal AC, averaged $13 \pm 1 \%$ in the cerebral cortex and only $7 \pm 1 \%$ in the hippocampus. The striatum, in which the predominant catecholamine is dopamine, showed a much higher response to this stimulant $(56 \pm 3 \%)$ as compared to the $\beta \mathrm{AR}$ response in the other regions; nevertheless, all three responses were statistically significant ( $p<0.0001$ for each). Clonidine, an $\alpha_{2}$ AR agonist, 
Table I Control Values for Forebrain Regions on PN75

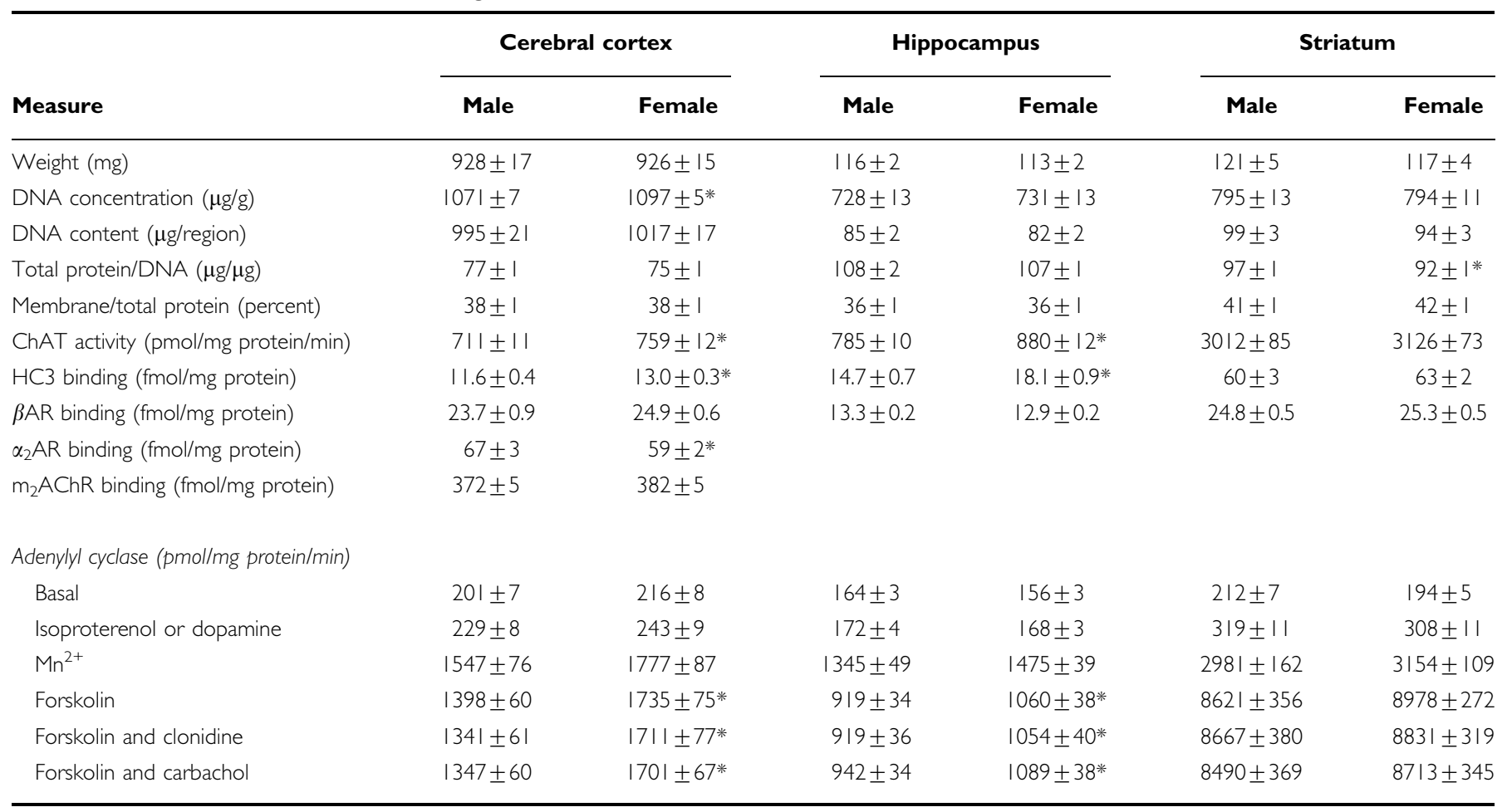

Values were compiled from all three control cohorts: those receiving saline injections on GDI7-19, PNI-3, or PN7-9. Across all regions, females display a lower overall total protein/DNA ratio (main effect of sex, $p<0.0007$ ), higher ChAT activity $(p<0.000 \mathrm{I}$ ) and higher HC3 binding $(p<0.0002)$. Across all regions and AC measures, females display higher activity than males $(p<0.003)$. Isoproterenol was used in the cerebral cortex and hippocampus, whereas dopamine was used in the striatum.

*Significant difference between males and females.

Table 2 Control Values for Cerebellum

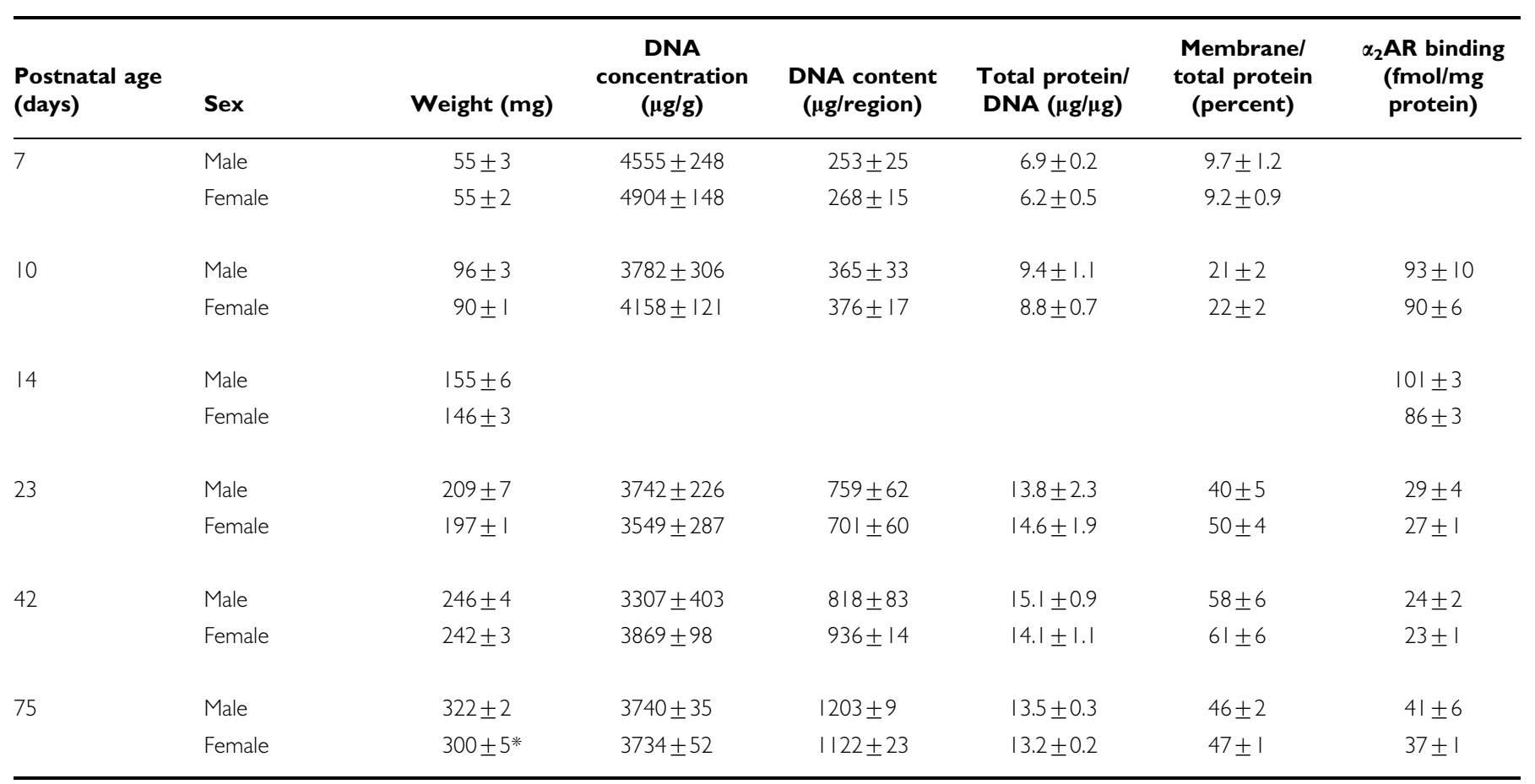

*Significant difference between males and females. 
elicited a small but significant $(p<0.03)$ inhibitory effect on forskolin-stimulated AC activity that was regionally specific (main effect of region, $p<0.05$ ), limited to the cerebral cortex $(p<0.003)$ but without sex-selectivity. Similarly, the $\mathrm{m}_{2} \mathrm{AChR}$ agonist carbachol elicited small but significant decreases in forskolin-stimulated AC activity in the cerebral cortex $(p<0.02)$ and striatum $(p<0.05)$ but not in the hippocampus.

\section{Effects on General Development and Growth}

All dams treated with Dex on GD17-19 delivered their litters at the proper time (during GD22) and there were no adverse effect on litter size or on offspring sex ratios. Control dams had an average of $11 \pm 1$ pups compared to $12 \pm 1$ in each of the three Dex treatment groups. The percentage of male offspring was $51 \pm 3 \%$ in controls, compared to $49 \pm 4$, $42 \pm 5$, and $56 \pm 3 \%$ at Dex doses of $0.05,0.2$, and $0.8 \mathrm{mg} / \mathrm{kg}$, respectively. Nevertheless, there was gross impairment of somatic growth evident at both 0.2 and $0.8 \mathrm{mg} / \mathrm{kg}$, with deficits reaching $20 \%$ in the immediate postnatal period in the latter group (Figure 1a). Body weights returned to normal by the second postnatal week in the $0.2 \mathrm{mg} / \mathrm{kg}$ group but did not approach normal values until adolescence or young adulthood in the high dose group. Weight deficits were not seen at the lowest Dex dose, $0.05 \mathrm{mg} / \mathrm{kg}$.

Shifting the Dex treatment to the early postnatal period resulted in increased somatic growth impairment, with significant deficits even at $0.05 \mathrm{mg} / \mathrm{kg}$ and reaching $30 \%$ deficits at the highest Dex dose (Figure 1b). Whereas body weights again approached normal values by adolescence in animals given 0.05 or $0.2 \mathrm{mg} / \mathrm{kg}$, the group receiving the highest dose remained subnormal into adulthood. Dex administration slightly later in the postnatal period, on PN7-9, also elicited initial weight deficits (Figure 1c), significant at all doses but smaller overall than the deficits seen immediately after treatment on PN1-3 ( $p<0.0001$ for treatment $\times$ regimen). Again, the group given $0.8 \mathrm{mg} / \mathrm{kg}$ displayed persistent body weight reductions of $10-15 \%$ in adulthood.

In contrast to the adverse effects on somatic growth, forebrain region weights were much less affected on PN75. At the lowest Dex dose, there was a tendency, at the margin of statistical significance, toward reduced region weight with the GD17-19 regimen but neither of the postnatal regimens showed any effects (Figure 2a). Similarly, at $0.2 \mathrm{mg} / \mathrm{kg}$, there were no consistent effects on brain region weights (Figure $2 \mathrm{~b}$ ), even though this treatment elicited prolonged deficits in body weights during the postnatal brain growth spurt. However, raising the Dex dose to $0.8 \mathrm{mg} / \mathrm{kg}$ did produce significant reductions in forebrain regional weights in adulthood (Figure 2c). Deficits were significant overall with the PN7-9 regimen $(p<0.02)$, averaging $5-10 \%$ below normal, across the three forebrain regions and in addition, effects on the cerebral cortex were significant assessed across all three treatment regimens $(p<0.0001)$, again in the range of $5-10 \%$ deficits.

For all the Dex regimens and doses, effects on body and brain region weights were exerted equally toward males and females, as evidenced by an absence of treatment $\times$ sex interactions.
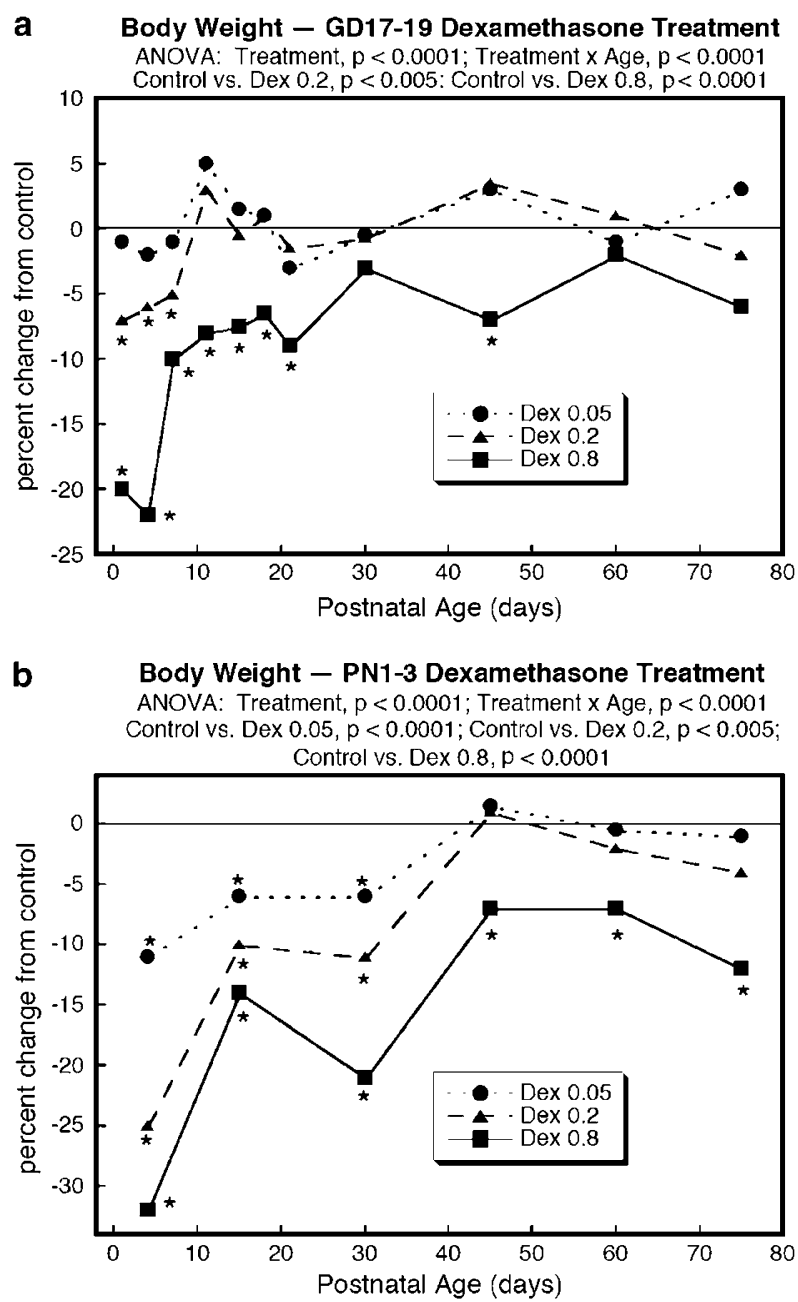

C Body Weight - PN7-9 Dexamethasone Treatment ANOVA: Treatment, $p<0.0001$; Treatment $x$ Age, $p<0.0001$ Control vs. Dex 0.05, $p<0.0001$; Control vs. Dex 0.2, $p<0.005$ Control vs. Dex $0.8, \mathrm{p}<0.0001$

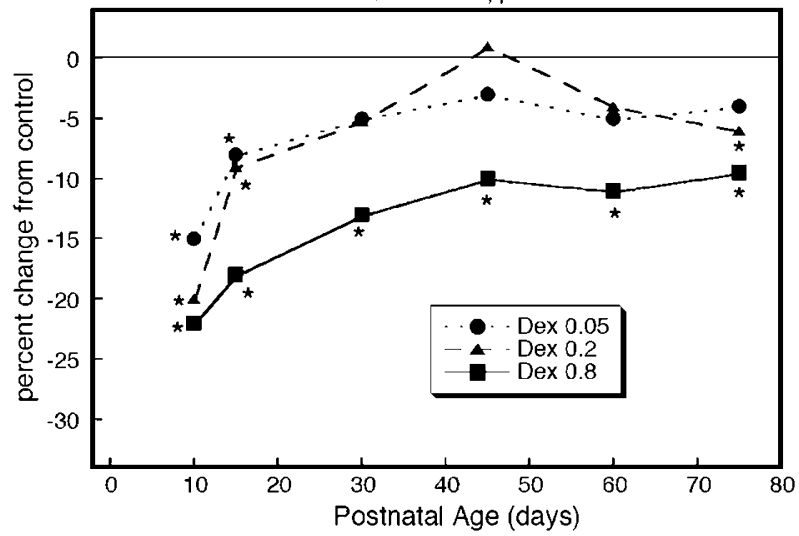

Figure I Effects of Dex regimens on body weights, presented as the percent change from control values: treatment on (a) GDI7-19, (b) PNI3, and (c) PN7-9. ANOVA across all doses and ages, and both sexes, appears at the top of each panel and asterisks denote individual values that differ significantly from the corresponding control. Standard errors (not shown) were typically $1-3 \%$. Effects for males and females were combined because of the absence of treatment $x$ sex interactions. Control weights $(\mathrm{g})$ at each of the II sequential age points were: male, $7.2 \pm 0.1,10.9 \pm 0.1$, $15.6 \pm 0.1,23.5 \pm 0.4,33.6 \pm 0.6,39.7 \pm 0.5,52.7 \pm 0.5,104 \pm 2,235 \pm 4$, $366 \pm 6, \quad 451 \pm 6$; female, $6.8 \pm 0.1, \quad 10.3 \pm 0.2, \quad 15.0 \pm 0.1, \quad 22.5 \pm 0.2$, $32.0 \pm 0.6,37.8 \pm 0.5,50.8 \pm 0.7,96 \pm 2,179 \pm 3,232 \pm 5,281 \pm 6$ 


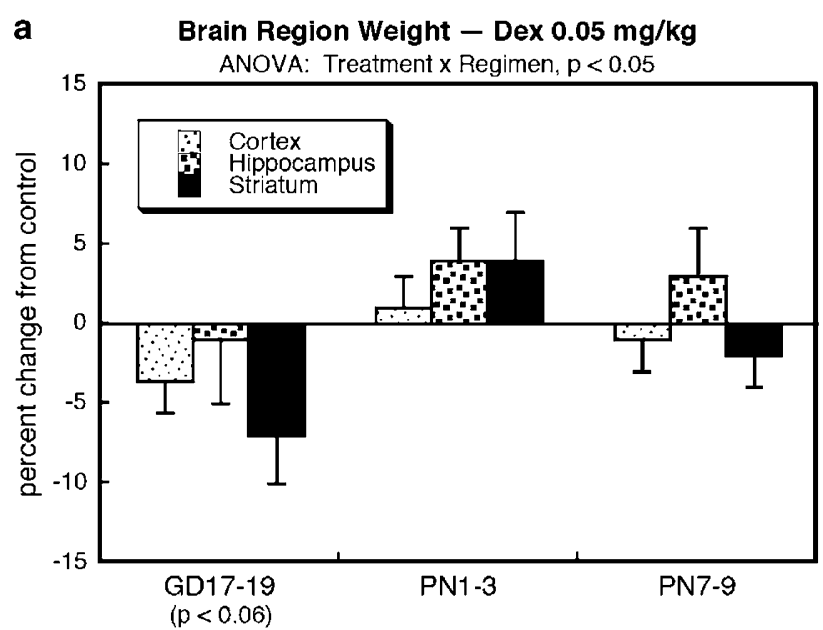

b $\quad$ Brain Region Weight - Dex $0.2 \mathrm{mg} / \mathrm{kg}$

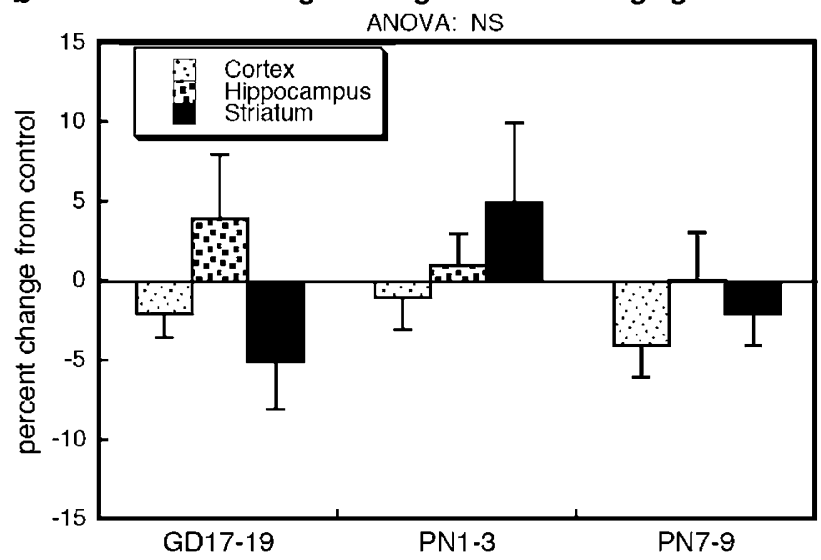

C Brain Region Weight - Dex $0.8 \mathrm{mg} / \mathrm{kg}$

ANOVA: Treatment, $p<0.04$; Treatment $x$ Regimen, $p<0.04$ Treatment $x$ Region, $p<0.05$ : Cerebral Cortex $p<0.0001$

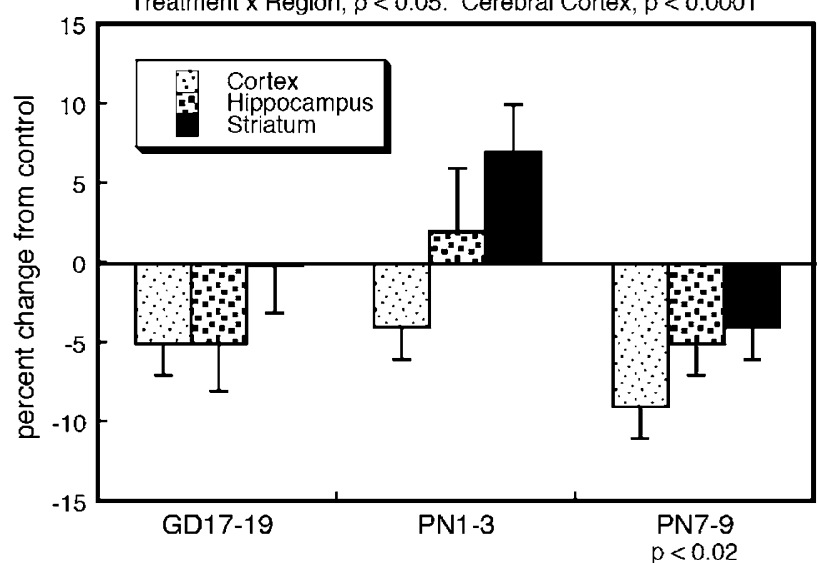

Figure 2 Effects of Dex regimens on brain region weights evaluated on PN75 and presented as the percent change from control values shown in Table I: treatment with (a) $0.05 \mathrm{mg} / \mathrm{kg}$, (b) $0.2 \mathrm{mg} / \mathrm{kg}$, and (c) $0.8 \mathrm{mg} / \mathrm{kg}$. ANOVA across regimens, regions, and both sexes appears at the top of each panel and, where a treatment $\times$ regimen interaction was found, lower-order tests for each regimen are shown at the bottom. Within each regimen, tests of significance for individual regions were not carried out because of the absence of treatment $\times$ region interactions, and similarly, effects for males and females were combined because of the absence of treatment $\times$ sex interactions. Across all regimens, doses and regions, and both sexes, ANOVA identified interactions of treatment $\times$ regimen $(p<0.07)$ and treatment $\times$ region $(p<0.06)$. NS, not significant.

\section{Effects on Indices of Cell Number and Size}

Global ANOVA across all four measures related to cell number and size (DNA concentration, DNA content, total protein/DNA ratio, membrane/total protein ratio) indicated a significant main treatment effect $(p<0.0001)$ that differed with regard to region and measure: $p<0.03$ for the interaction of treatment $\times$ region, $p<0.003$ for treatment $\times$ measure, and $p<0.04$ for treatment $\times$ region $\times$ measure. Accordingly, we examined each of the four measures separately, but combined the effects on males and females because of the absence of treatment $\times$ sex interactions.

Overall, the different Dex regimens and doses elicited a significant deficit in neural cell packing density and total cell number in adulthood, as assessed by the DNA concentration and content $(p<0.005)$. The magnitude of effect was small, generally $5 \%$, but relatively consistent. Even the lowest Dex dose elicited significant overall reductions in DNA concentration (Figure 3a) and these effects were quite similar to those seen at $0.2 \mathrm{mg} / \mathrm{kg}$ (Figure $3 \mathrm{~b}$ ) or $0.8 \mathrm{mg} / \mathrm{kg}$ (Figure 3c). For DNA content, the pattern was comparable, although there were some regional and dose differences not seen for DNA concentration. At $0.05 \mathrm{mg} / \mathrm{kg}$, significant deficits in DNA content were limited to the striatum (Figure 3d) but the effect across the three regions was not distinguishable from the significant overall deficit seen for DNA concentration (no significant treatment $\times$ measure interaction). Likewise, for the $0.2 \mathrm{mg} /$ $\mathrm{kg}$ group (Figure 3e), there was the same small but significant effect on DNA content. In contrast, at the highest Dex dose (Figure 3f), the deficits in DNA content reached as high as $10-15 \%$ in the cerebral cortex, and the overall effects were significantly greater than those seen for DNA concentration (treatment $\times$ measure, $p<0.007$ ), reflecting the lower cell packing density (reduced DNA concentration) superimposed on a reduced region weight.

Unlike the consistent reductions seen in the DNA biomarkers, the effects of Dex treatments on the total protein/DNA ratio were not monotonic. At the lowest dose, there was a small but significant overall reduction in this index of cell size (Figure 4a), which was no longer evident when the dose was raised to $0.2 \mathrm{mg} / \mathrm{kg}$ (Figure $4 \mathrm{~b}$ ). At the highest Dex dose, there was a significant increase in the ratio in cerebral cortex in the group receiving Dex on PN7-9 (Figure 4c). In fact, examination of the membrane/total protein ratio reinforced the cerebral cortex as a specific Dex target for the PN7-9 regimen. Across all three doses, the ratio was reduced in the cerebral cortex $(p<0.02)$ but not in the other regions. At $0.05 \mathrm{mg} / \mathrm{kg}$ (Figure $4 \mathrm{~d}$ ), the effect was significant only in the cerebral cortex; at $0.2 \mathrm{mg} / \mathrm{kg}$ (Figure 4e), the main effect of Dex also was limited to the PN7-9 regimen and was again greatest in the cerebral cortex; likewise, at $0.8 \mathrm{mg} / \mathrm{kg}$, only the cerebral cortex was significantly affected (Figure $4 \mathrm{f}$ ).

\section{Effects on Cholinergic Presynaptic Indices}

Across the two cholinergic presynaptic markers, ChAT and HC3 binding, there were interactions of Dex treatment with sex, regimen, region, and measure: $p<0.005$ for treatment $\times$ sex, $p<0.07$ for treatment $\times$ measure, $p<0.05$ for 

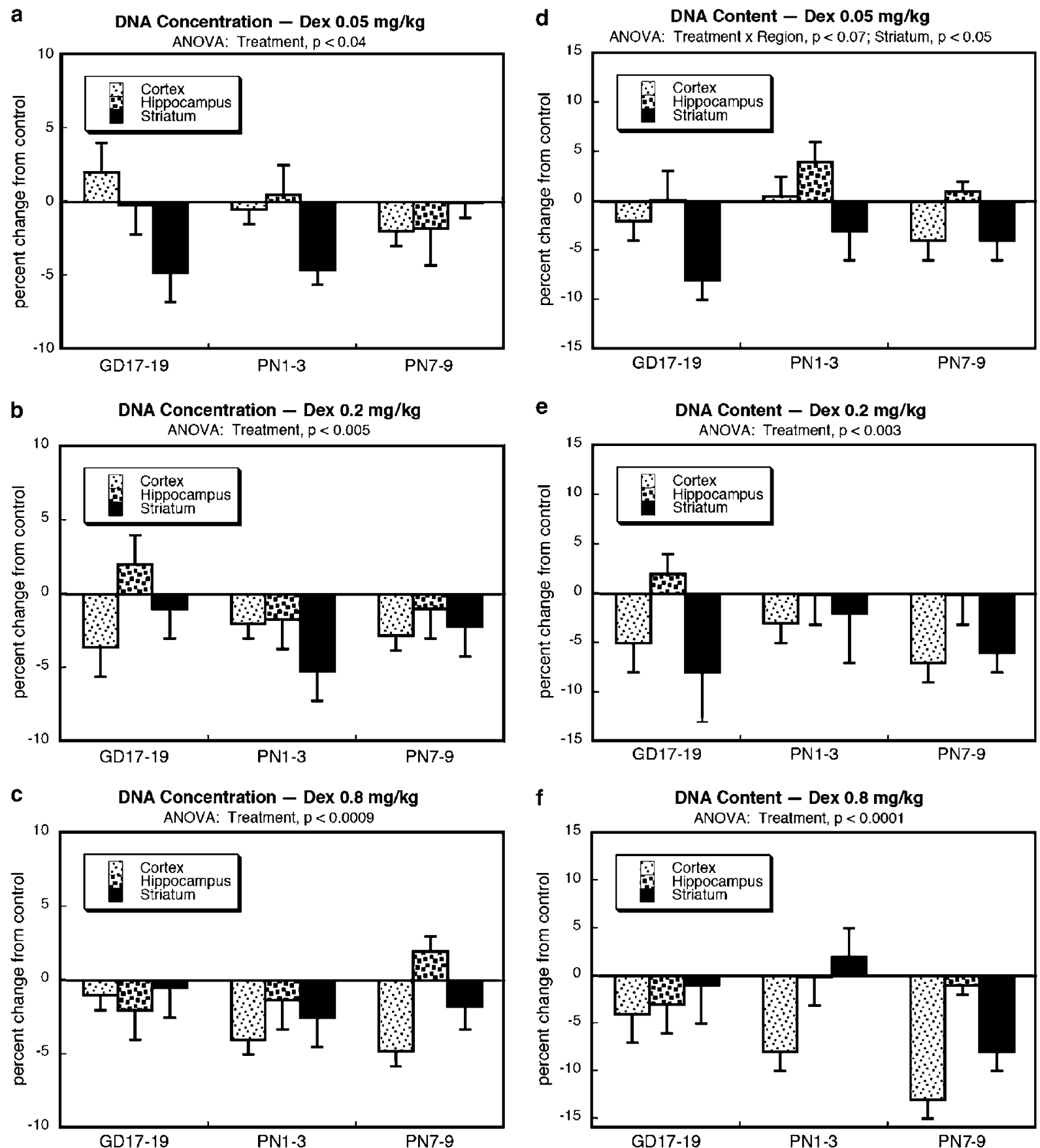

Figure 3 Effects of Dex regimens on DNA concentration ( $a, b, c)$ and DNA content ( $d, e, f)$, evaluated on PN75 and presented as the percent change from control values shown in Table I: treatment with (a, d) $0.05 \mathrm{mg} / \mathrm{kg},(\mathrm{b}, \mathrm{e}) 0.2 \mathrm{mg} / \mathrm{kg}$, and (c, f) $0.8 \mathrm{mg} / \mathrm{kg}$. ANOVA across regimens, regions, and both sexes appears at the top of each panel. Lower-order tests for each regimen were not evaluated because of the absence of treatment $\times$ regimen interactions, and similarly, effects for males and females were combined because of the absence of treatment $\times$ sex interactions. Across all regimens, doses and regions, both sexes, and both measures, ANOVA identified a main effect of treatment $(p<0.005)$ and interactions of treatment $\times$ region $(p<0.03)$, and treatment $\times$ measure $(p<0.04)$.

treatment $\times$ regimen $\times$ measure, $p<0.09$ for treatment $\times$ region $\times$ measure, and $p<0.1$ for treatment $\times$ regimen $\times$ region. Owing to the strong interaction with sex, we contrasted the effects on males and females for each of the measures.

In males, $0.05 \mathrm{mg} / \mathrm{kg}$ of Dex elicited an overall increase in ChAT activity that was at the margin of significance (Figure 5a). Raising the dose to $0.2 \mathrm{mg} / \mathrm{kg}$ produced a correspondingly larger effect on ChAT that did achieve statistical significance (Figure 5b), but increasing Dex exposure to $0.8 \mathrm{mg} / \mathrm{kg}$ led to a loss of the promotional actions (Figure $5 \mathrm{c}$ ). In females, there was no effect at $0.05 \mathrm{mg} / \mathrm{kg}$ (Figure $5 \mathrm{~d}$ ). At the intermediate Dex dose, there were distinctly different outcomes that depended upon the developmental period in which Dex was administered (Figure 5e): increases were seen with the GD17-19 regimen but either of the postnatal regimens elicited significant decreases, the opposite of what was obtained in males. The 

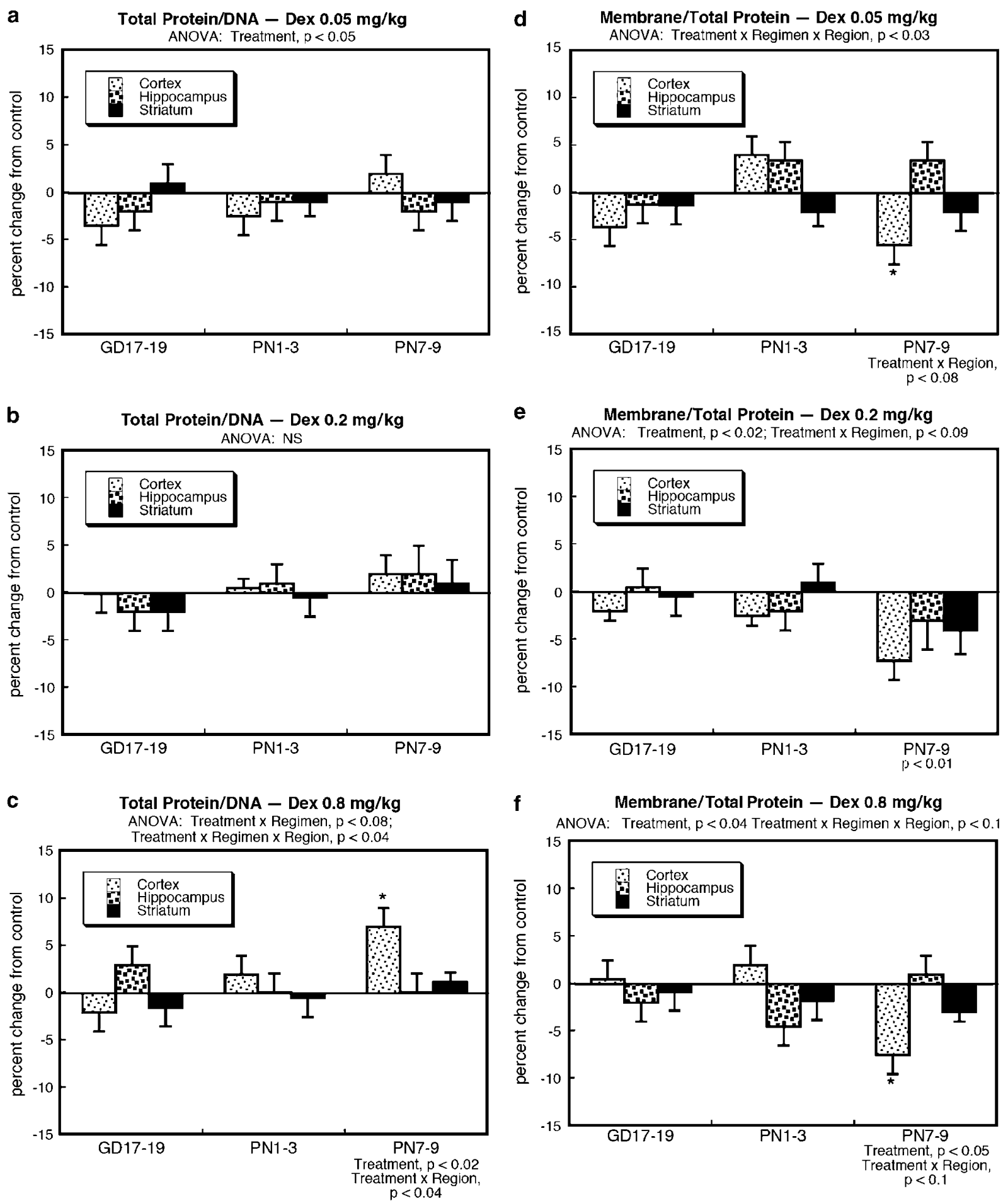

Figure 4 Effects of Dex regimens on the total protein/DNA ratio ( $a, b, c)$ and the membrane/total protein ratio (d, e, f), evaluated on PN75 and presented as the percent change from control values shown in Table I: treatment with (a, d) $0.05 \mathrm{mg} / \mathrm{kg},(\mathrm{b}, \mathrm{e}) 0.2 \mathrm{mg} / \mathrm{kg}$, and (c, f) $0.8 \mathrm{mg} / \mathrm{kg}$. ANOVA across regimens, regions, and both sexes appears at the top of each panel and, where a treatment $\times$ regimen interaction was found, lower-order tests for each regimen are shown at the bottom. Within each regimen, tests of significance for individual regions (asterisks) were carried out only where there was a treatment $\times$ region interaction, and otherwise, only main treatment effects are presented. Effects for males and females were combined because of the absence of treatment $\times$ sex interactions. Across all regimens, doses and regions, both sexes, and both measures, ANOVA identified a main effect of treatment $(p<0.02)$ and interactions of treatment $\times$ measure $(p<0.04)$ and treatment $\times$ regimen $\times$ region $\times$ measure $(p<0.05)$. NS, not significant.

same trends were present at the highest Dex dose but did not achieve statistical significance (Figure 5f); however, this outcome was also not distinguishable from the significant effect seen with $0.2 \mathrm{mg} / \mathrm{kg}$, so the lack of significance at the higher dose should not be interpreted as an absence of a biologic effect.

As control males had significantly lower overall ChAT activities than females (Table 1), the Dex-induced increase 
a ChAT Activity - Male - Dex $0.05 \mathrm{mg} / \mathrm{kg}$

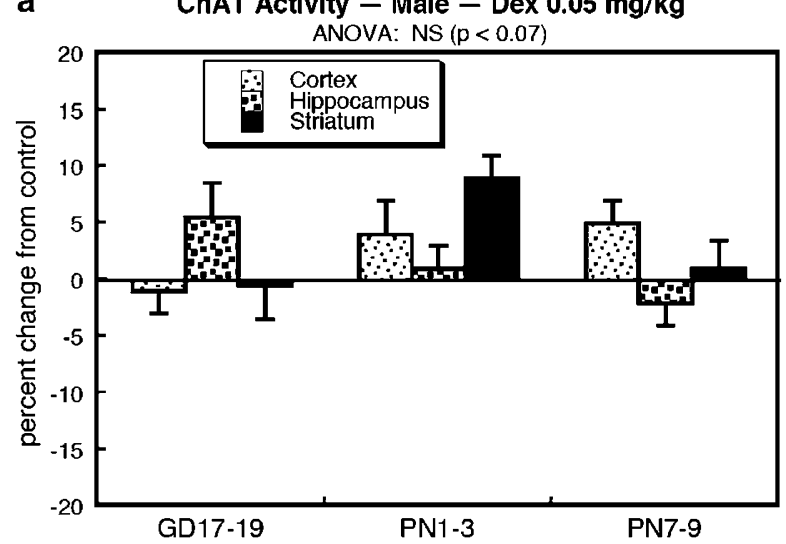

b ChAT Activity - Male - Dex $0.2 \mathrm{mg} / \mathrm{kg}$

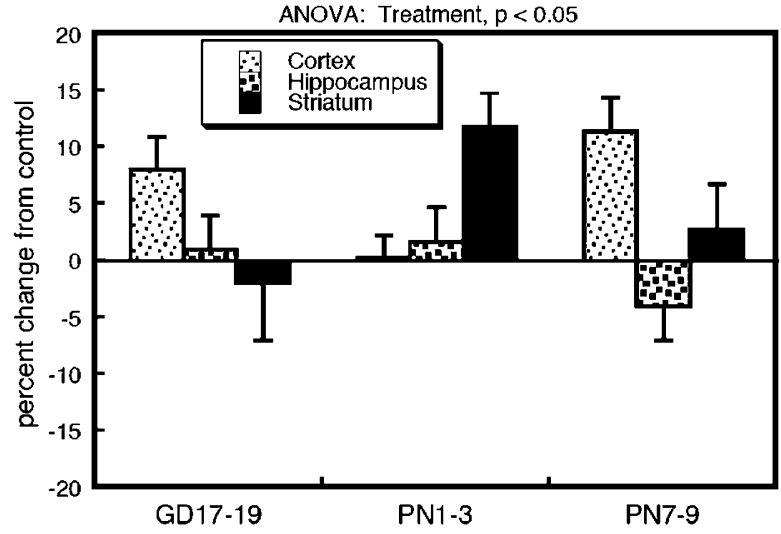

C

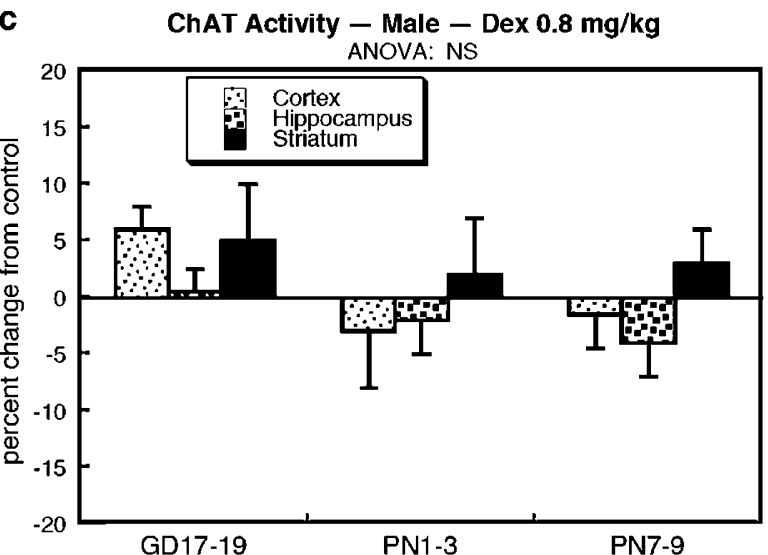

d

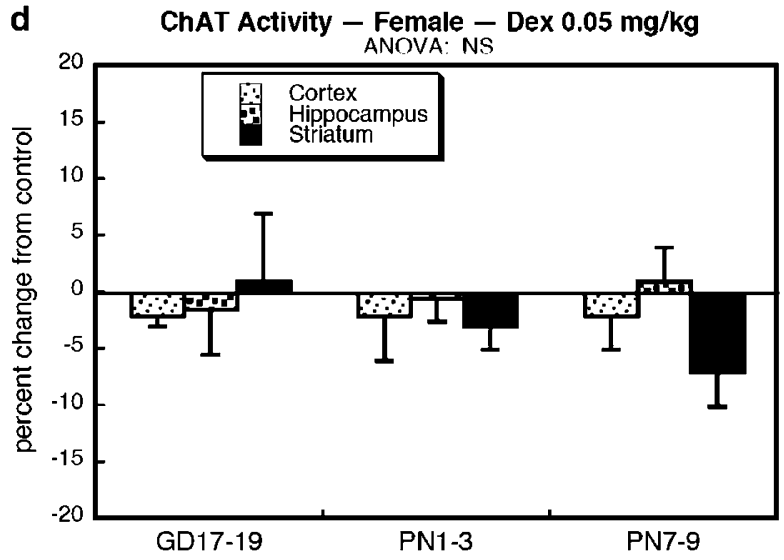

e ChAT Activity - Female - Dex $0.2 \mathrm{mg} / \mathrm{kg}$

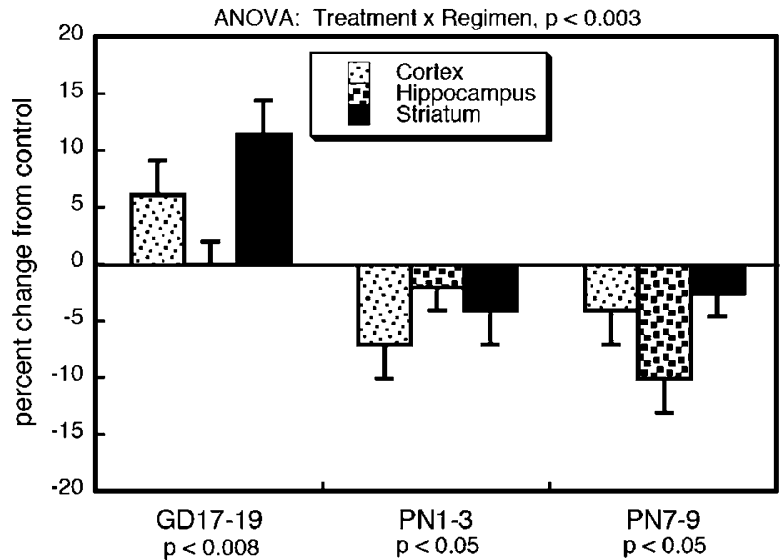

f ChAT Activity - Female - Dex $0.8 \mathrm{mg} / \mathrm{kg}$

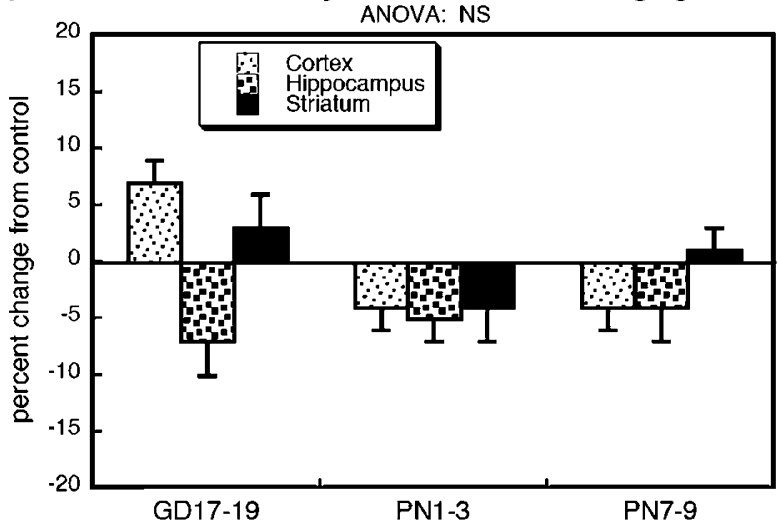

Figure 5 Effects of Dex regimens on ChAT activity, evaluated on PN75 and presented as the percent change from control values shown in Table I: treatment with (a, d) $0.05 \mathrm{mg} / \mathrm{kg}$, (b, e) $0.2 \mathrm{mg} / \mathrm{kg}$, and (c, f) $0.8 \mathrm{mg} / \mathrm{kg}$. Across all regimens, doses and regions, and both sexes, ANOVA identified interactions of treatment $\times$ regimen $(p<0.06)$, treatment $\times \operatorname{sex}(p<0.08)$, and treatment $\times$ regimen $\times \operatorname{sex}(p<0.09)$, necessitating separation of the data for males $(a$, b c) and females ( $d, e, f)$. ANOVA across regimens and regions appears at the top of each panel and, where a treatment $\times$ regimen interaction was found, lower-order tests for each regimen are shown at the bottom. Within each regimen, tests of significance for individual regions were not carried out because of the absence of treatment $\times$ region interactions. NS, not significant.

in males and decrease in females would tend to eliminate sex differences. To test this hypothesis, we evaluated the main effect of sex for each of the treatment groups. In controls, the sex difference was highly significant $(p<0.0001)$ and this was reduced but not totally eliminated by Dex treatment. The sex difference was not significant in the groups receiving 0.05 or $0.2 \mathrm{mg} / \mathrm{kg}$ ( $p<0.09$ for each) but remained significant at $0.8 \mathrm{mg} / \mathrm{kg}(p<0.003)$, albeit with only one-fourth of the overall sex difference seen in controls (average difference of 2.5 vs 10\%).

In contrast to the modest, but significant effects on ChAT, Dex had far more robust, sex-selective effects on HC3 binding. Males showed a highly significant overall increase evoked by Dex (main effect, $p<0.0005$ ), whereas the overall effect in females was not significant. At $0.05 \mathrm{mg} / \mathrm{kg}$, Dex elicited a mixed pattern of small increases and decreases in 

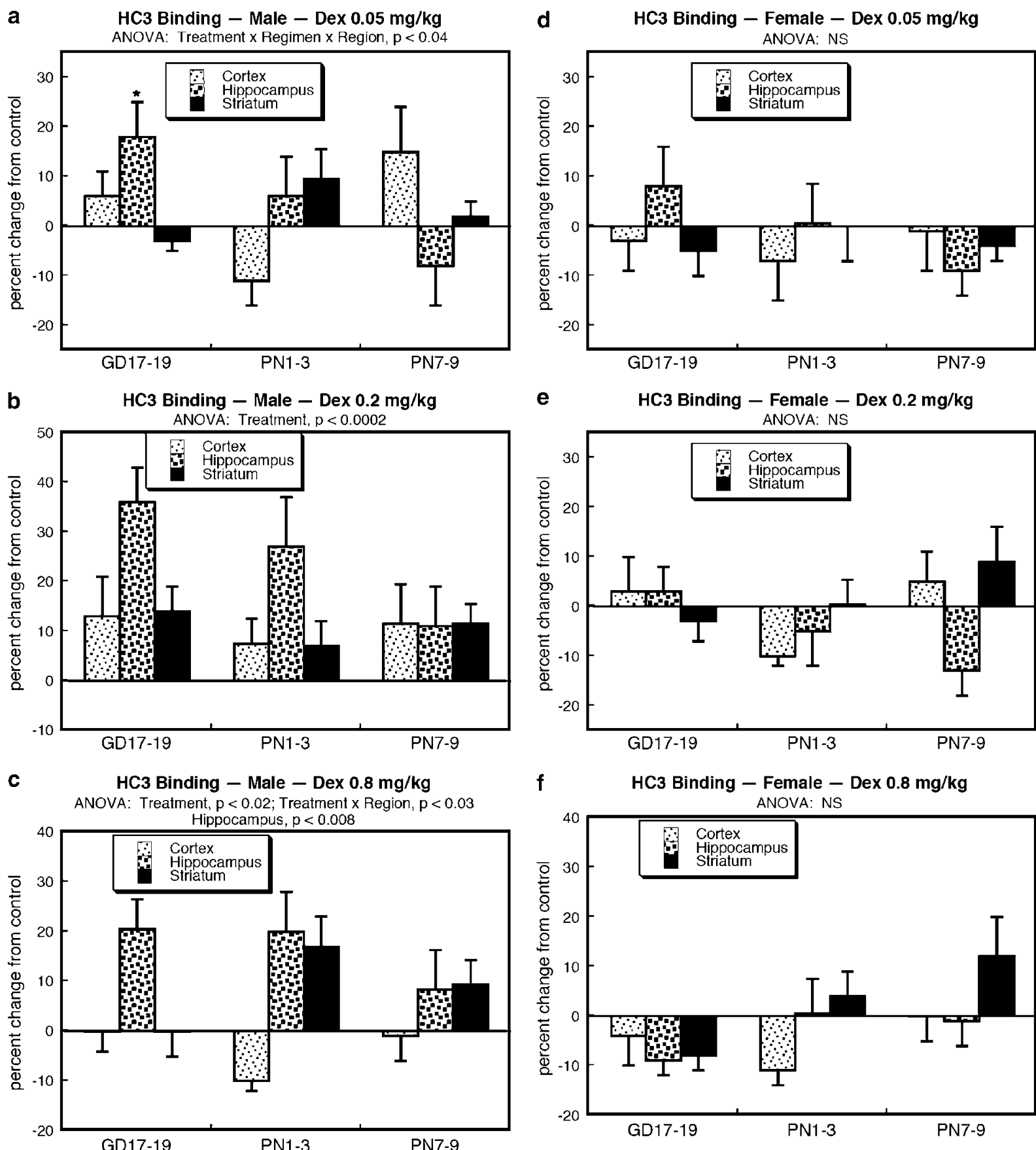

Figure 6 Effects of Dex regimens on HC3 binding, evaluated on PN75 and presented as the percent change from control values shown in Table I: treatment with (a, d) $0.05 \mathrm{mg} / \mathrm{kg}$, (b, e) $0.2 \mathrm{mg} / \mathrm{kg}$, and (c, f) $0.8 \mathrm{mg} / \mathrm{kg}$. Across all regimens, doses and regions, and both sexes, ANOVA identified a main treatment effect $(p<0.03)$ and an interaction of treatment $\times \operatorname{sex}(p<0.009)$, necessitating separation of the data for males $(a, b, c)$ and females $(d, e, f)$ ANOVA across regimens and regions appears at the top of each panel. In panel (a), the asterisk denotes the individual region showing statistically significant differences (validated by the treatment $\times$ regimen $\times$ region interaction), whereas in panels $(b)$ and $(c)$, lower-order tests for each regimen or for each region within a given regimen were not evaluated because of the absence of treatment $\times$ regimen interactions. Two of the numbers in panels (b) and (e) (hippocampus for males and females for the GDI7-19 regimen at $0.2 \mathrm{mg} / \mathrm{kg}$ Dex) were published in a previous report (Kreider et al, 2005b). NS, not significant.

males, with one effect (hippocampus for the GD17-19 regimen) achieving statistical significance (Figure 6a). When the dose was raised to $0.2 \mathrm{mg} / \mathrm{kg}$, there was a highly significant overall augmentation of HC3 binding, with the largest effect, up to a $30 \%$ increase, seen in the hippocampus (Figure $6 \mathrm{~b}$ ). At $0.8 \mathrm{mg} / \mathrm{kg}$, the dose that elicited somatic growth deficits, there were still significant increases in HC3 binding in males but the magnitude of the effect was smaller, again remaining greatest for the hippocampus (Figure 6c). For females, none of the Dex doses or regimens elicited significant changes in HC3 binding (Figure 6d, e and $\mathrm{f}$ ). Since control males exhibited significantly lower HC3 binding than females (Table 1), the sex-selective increase evoked by Dex administration offset these normal 
a $\quad$ BAR Binding - Dex $0.05 \mathrm{mg} / \mathrm{kg}$

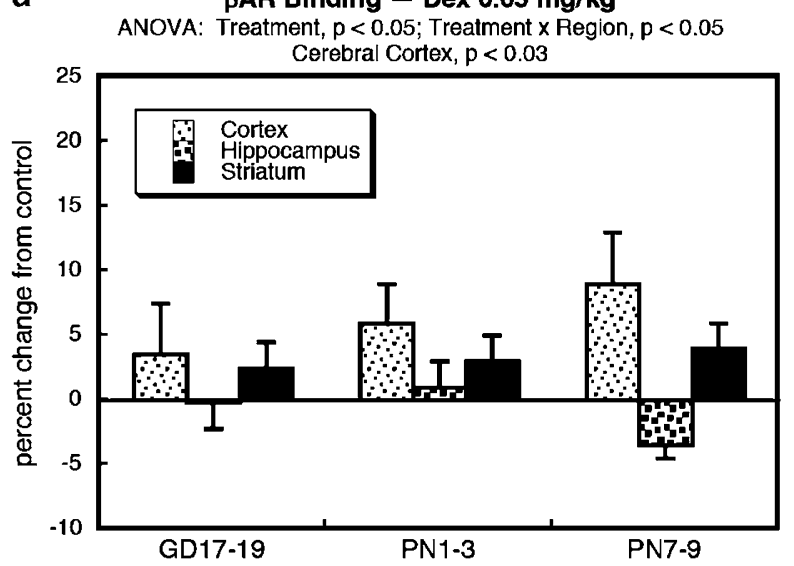

b $\quad$ BAR Binding - Male - Dex $0.2 \mathrm{mg} / \mathbf{k g}$ ANOVA: Treatment, $p<0.0004$; Treatment $x$ Region, $p<0.007$ Treatment $x$ Regimen $x$ Region, $\mathrm{p}<0.09$

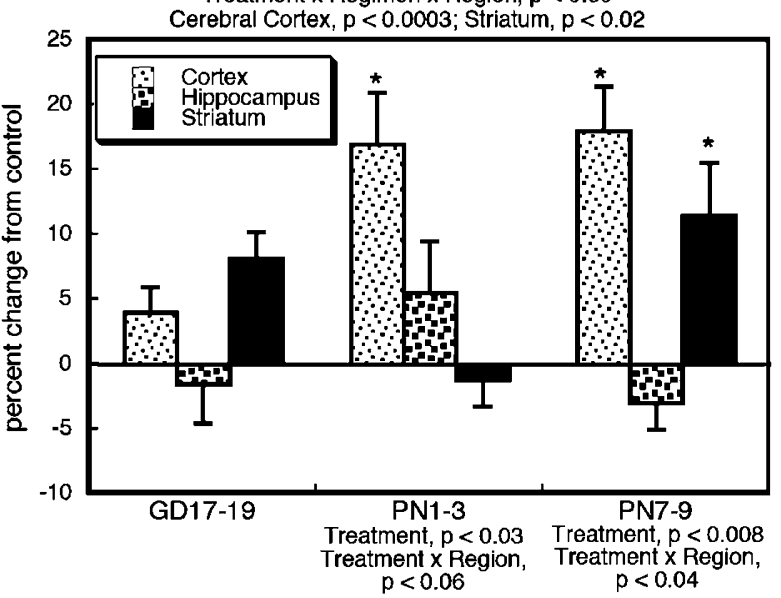

C

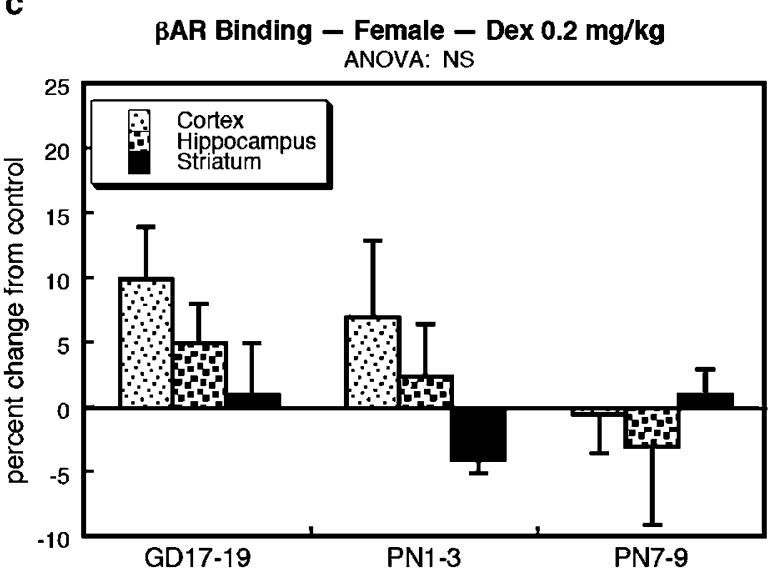

d

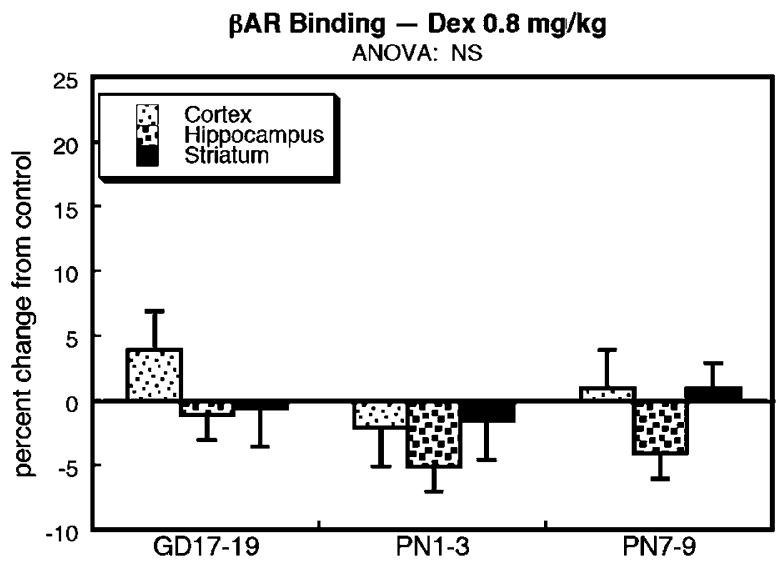

Figure 7 Effects of Dex regimens on $\beta A R$ binding, evaluated on PN75 and presented as the percent change from control values shown in Table I: treatment with (a) $0.05 \mathrm{mg} / \mathrm{kg}$, (b, c) $0.2 \mathrm{mg} / \mathrm{kg}$, and (d) $0.8 \mathrm{mg} / \mathrm{kg}$. Across all regimens, doses and regions, and both sexes, ANOVA identified a main treatment effect $(p<0.000 \mathrm{l})$ and interactions of treatment $\times$ region $(p<0 . \mathrm{I})$ and treatment $\times \operatorname{sex}(p<0.02)$, but the sex differences were significant only for treatment with $0.2 \mathrm{mg} / \mathrm{kg}$. Accordingly, effects for males and females were combined for presentation of results at $0.05 \mathrm{mg} / \mathrm{kg}$ (a) and $0.8 \mathrm{mg} / \mathrm{kg}$ (d), but appear separately for males (b) and females (c) at the intermediate dose. ANOVA across regimens and regions appears at the top of each panel and, where a treatment $\times$ regimen interaction was found, lower-order tests for each regimen are shown at the bottom. Within each regimen, tests of significance for individual regions (asterisks) were carried out only where there was a treatment $\times$ region interaction, and otherwise, only main treatment effects are presented. NS, not significant.

sex differences: whereas there was a significant main effect of sex on HC3 binding in controls $(p<0.0001)$, this difference was abolished at all doses of Dex: $p<0.2$ at $0.05 \mathrm{mg} / \mathrm{kg}$ and $p<0.4$ at 0.2 or $0.8 \mathrm{mg} / \mathrm{kg}$.

\section{Effects on Receptor Binding}

Across all regimens, doses and regions, and both sexes, there was a significant main effect of Dex treatment on $\beta$ AR binding $(p<0.0001)$ as well as treatment interactions with sex and region $(p<0.02$ for treatment $\times$ sex, $p<0.1$ for treatment $\times$ region). Upon examination of each of the Dex treatments, it was apparent that the sex interaction was limited to the $0.2 \mathrm{mg} / \mathrm{kg}$ dose $(p<0.05$ for the treatment $\times$ sex interaction, but no significant interaction for the other doses), so effects on males and females were combined for presentation for the other two doses. Treatment with $0.05 \mathrm{mg} / \mathrm{kg}$ elicited significant $\beta$ AR upregulation, limited to the cerebral cortex (Figure 7a). Raising the dose to $0.2 \mathrm{mg} / \mathrm{kg}$ enhanced the effect but also revealed a preferential action in males (Figure $7 \mathrm{~b}$ ), with a large increase in the cerebral cortex and a smaller, but significant enhancement in the striatum; hippocampal $\beta$ ARs remained unaffected. This dose also revealed a critical period for Dex effects on $\beta$ ARs, as there was a much smaller, nonsignificant effect with the GD17-19 regimen, whereas the effects with postnatal regimens were robust. In contrast to the effects in males, females showed no significant effects (Figure 7c). Finally, increasing the dose to $0.8 \mathrm{mg} / \mathrm{kg}$ led to a complete loss of the promotional effect of Dex on $\beta$ AR expression (Figure 7d).

Owing to limitations in the amounts of tissue available from hippocampus and striatum, $\alpha_{2} \mathrm{AR}$ and $\mathrm{m}_{2} \mathrm{AChR}$ binding were evaluated only in the cerebral cortex. For $\alpha_{2}$ ARs, ANOVA indicated a main Dex treatment effect $(p<0.008)$ and an interaction of treatment $\times$ sex $(p<0.0002)$, necessitating separation of values for males and females. In males, we obtained the same biphasic 
response that was seen for $\beta$ ARs, namely significant upregulation at $0.2 \mathrm{mg} / \mathrm{kg}$ that was lost when the dose was raised to $0.8 \mathrm{mg} / \mathrm{kg}$ (Figure $8 \mathrm{a}$ ). However, effects on $\alpha_{2} \mathrm{AR}$ binding did not display specificity for postnatal regimens and in fact, the greatest effect was obtained with treatment on GD17-19. Furthermore, whereas the $\beta \mathrm{AR}$ effect was selective for males, $\alpha_{2} \mathrm{AR}$ upregulation was also significant for females (Figure $8 b$ ).

Evaluation of $\mathrm{m}_{2} \mathrm{AChR}$ binding indicated no overall treatment effect or interaction of treatment $\times$ sex (Figure 8c).

\section{Effects on AC Signaling}

Across all regimens, doses, regions, both sexes, and the various AC measures, ANOVA indicated a global elevation of activity caused by Dex treatment (main effect, $p<0.0001$ ) and interactions of treatment $\times$ sex $(p<0.02)$, treatment $\times$ AC measure $(p<0.0001)$, treatment $\times$ sex $\times$ measure $(p<0.0008)$, and treatment $\times$ region $\times$ measure $(p<0.04)$. Accordingly, values for males and females were examined separately.

In the cerebral cortex, Dex administration evoked marked increases in AC activity that differed according to sex, treatment regimen, and specific AC stimulant. In males, at the lowest Dex dose, there were overall increases for the response to direct $\mathrm{AC}$ stimulants $\left(\mathrm{Mn}^{2+}\right.$, forskolin) but not for basal activity or the response to isoproterenol (Figure 9a). As a result, the response of isoproterenol relative to that of forskolin, which represents the effective coupling of $\beta$ ARs to the total G-protein-linked AC available for response (isoproterenol/forskolin response ratio), declined by about $10 \%$ overall $(p<0.005)$. Similarly, the specific response to clonidine showed a loss of the $\alpha_{2} \mathrm{AR}$ response. In controls, clonidine elicited an overall decrease in forskolin-stimulated AC activity $(0.96 \pm 0.01$ for the ratio of activity with/without clonidine), whereas the response was completely lost in the animals given Dex (ratio of $1.04 \pm 0.02$ across the three Dex regimens, $p<0.0001$ ). The same uncoupling was found for $\mathrm{m}_{2} \mathrm{AChRs}$ : the ratio of forskolin-stimulated AC with/without carbachol was $0.97 \pm 0.02$ in controls as compared to $1.03 \pm 0.02$ in the Dex groups $(p<0.03)$.

At the intermediate Dex dose $(0.2 \mathrm{mg} / \mathrm{kg})$, cerebrocortical $\mathrm{AC}$ activities in males showed even larger increases, up to $60 \%$ above control values (Figure $9 \mathrm{~b}$ ). Again, the largest effects were seen for responses to $\mathrm{Mn}^{2+}$ and forskolin, or forskolin in combination with other stimulants, whereas effects on basal and isoproterenol-stimulated AC were much

Figure 8 Effects of Dex regimens on cerebrocortical receptor binding for $\alpha_{2}$ ARs and $m_{2}$ AChRs, evaluated on PN75 and presented as the percent change from control values shown in Table I. For $\alpha_{2} A R s$, ANOVA across all regimens and doses, and both sexes identified a main treatment effect $(p<0.008)$ and a treatment $\times$ sex interaction $(p<0.0002)$, necessitating separation of the values for males (a) and females (b). For $m_{2} A C h R s$, there was no interaction of treatment $x$ sex, so effects on males and females were combined for presentation (c). ANOVA across regimens and treatments appears at the top of each panel. Main effects for each treatment are shown but lower-order tests for each regimen were not evaluated because of the absence of treatment $\times$ regimen interactions. NS, not significant. smaller or nonsignificant. There were also clear differences among the regimens, with smaller effects after GD17-19 treatment as compared to the postnatal regimens. Superimposed on these basic effects, the relative response to $\beta \mathrm{AR}$ stimulation once more displayed uncoupling, with a $20 \%$ decline in the isoproterenol/forskolin response ratio
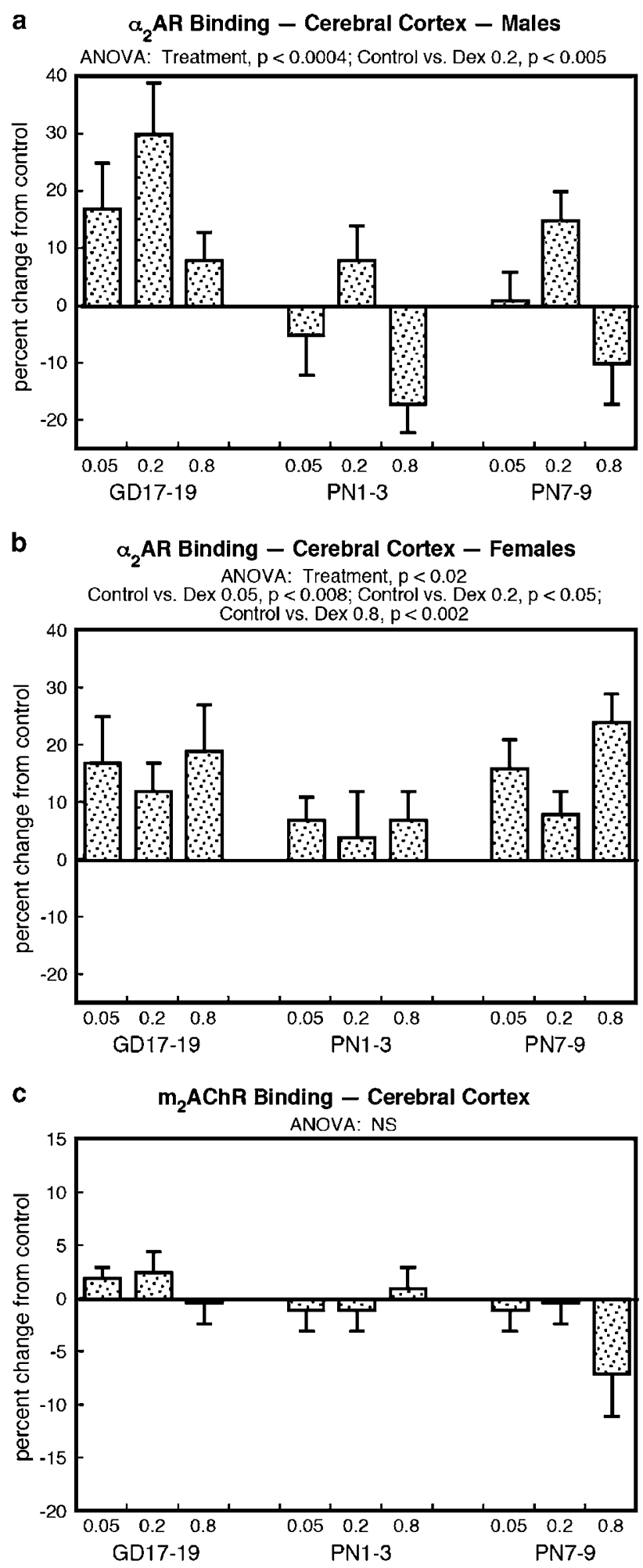
a Adenylyl Cyclase - Male Cerebral Cortex - Dex $0.05 \mathbf{~ m g} / \mathbf{k g}$ ANOVA: Treatment, $p<0.005$ Treatment $x$ Measure, $p<0.0001$ $\mathrm{Mn}^{2+}, \mathrm{p}<0.005$; Fsk, $\mathrm{p}<0.006$; Fsk+Clon, $\mathrm{p}<0.0001$; Fsk+Carb, $\mathrm{p}<0.0005$

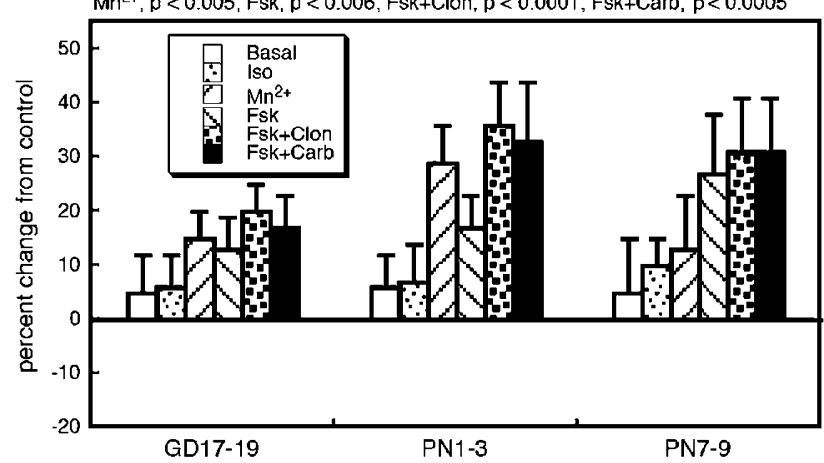

b Adenylyl Cyclase - Male Cerebral Cortex - Dex 0.2 mg/kg ANOVA: Treatment, $p<0.0004$. Treatment $x$ Measure $p<0.0001$

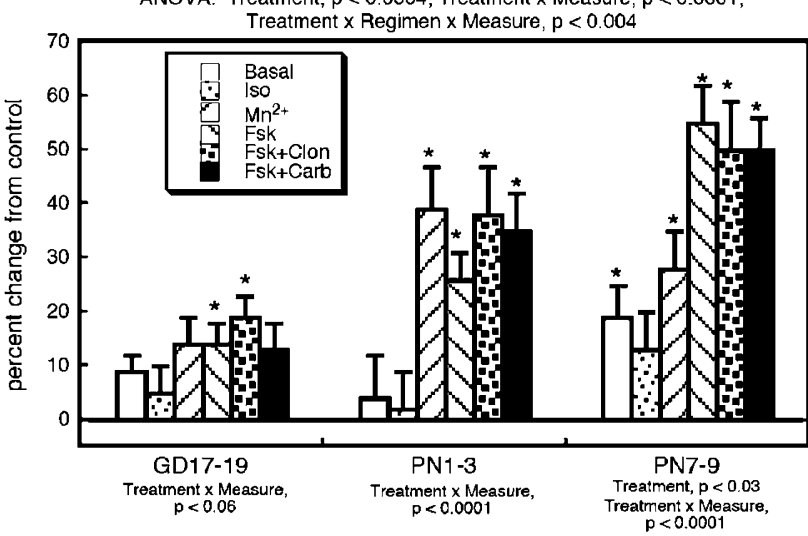

C Adenylyl Cyclase - Male Cerebral Cortex - Dex $0.8 \mathrm{mg} / \mathbf{k g}$ ANOVA: Treatment, $p<0.008$; Treatment $x$ Measure, $p<0.0001$ Treatment $\times$ Regimen $x$ Measure, $p<0.1$

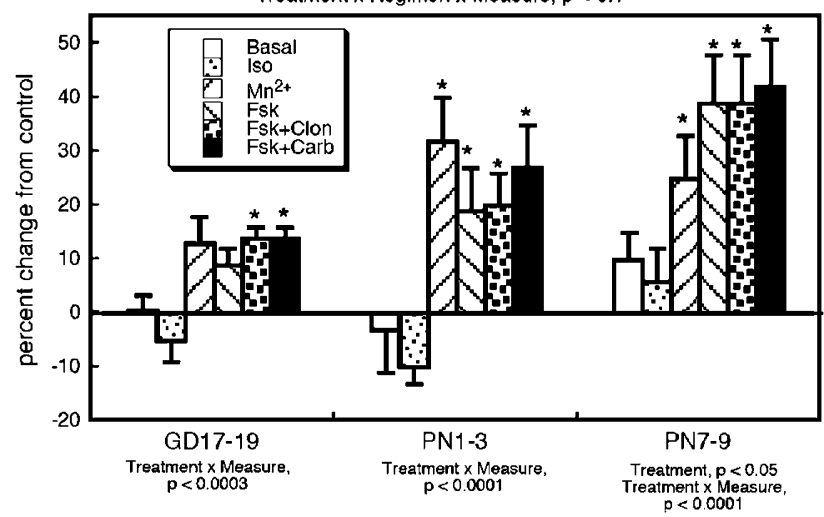

d

Adenylyl Cyclase - Female Cerebral Cortex - Dex 0.05 mg/kg ANOVA: Treatment $p<0.05$; Treatment $x$ Regimen, $p<0.04$;

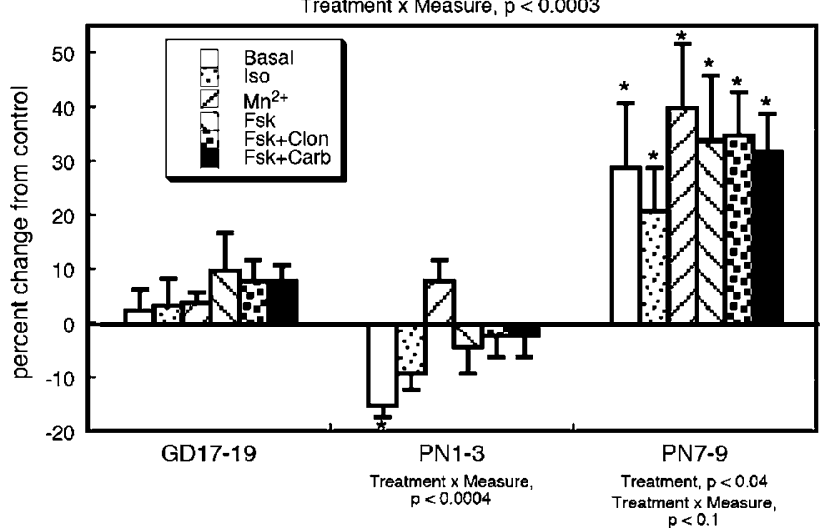

$p<0.1$

e Adenylyl Cyclase - Female Cerebral Cortex - Dex $0.2 \mathrm{mg} / \mathbf{k g}$

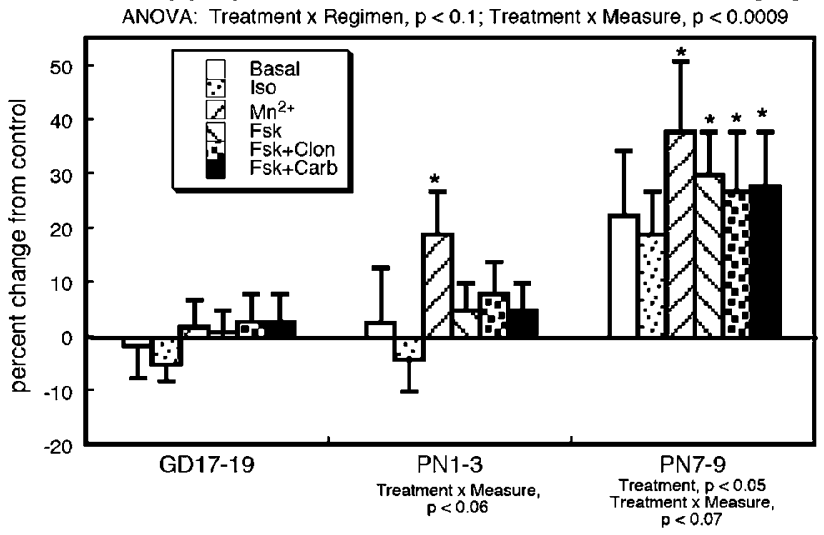

f

Adenylyl Cyclase - Female Cerebral Cortex - Dex $0.8 \mathrm{mg} / \mathrm{kg}$ ANOVA: Treatment $x$ Measure, $\mathrm{p}<0.0001 ; \mathrm{Mn}^{2+}, \mathrm{p}<0.05$

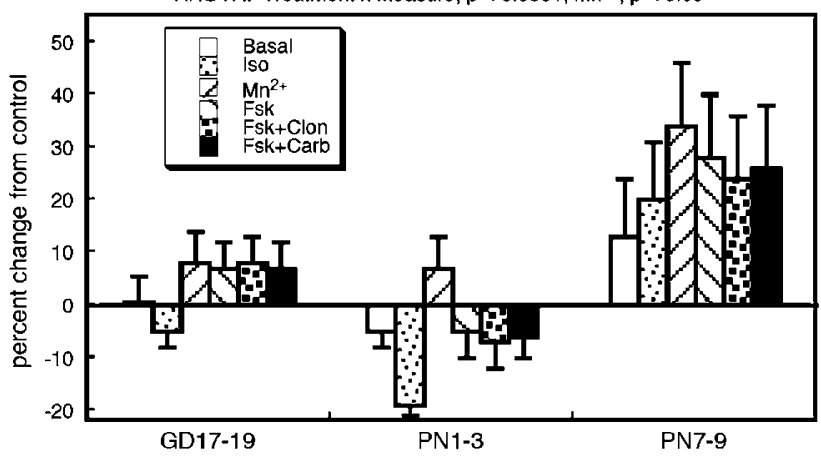

Figure 9 Effects of Dex regimens on cerebrocortical AC signaling, evaluated on PN75 and presented as the percent change from control values shown in Table l: treatment with (a, d) $0.05 \mathrm{mg} / \mathrm{kg}$, (b, e) $0.2 \mathrm{mg} / \mathrm{kg}$, and (c, f) $0.8 \mathrm{mg} / \mathrm{kg}$. Across all regimens, doses and AC measures, and both sexes, ANOVA identified a main treatment effect $(p<0.0001)$ and interactions of treatment $\times$ measure $(p<0.0001)$, treatment $\times$ regimen $\times$ measure $(p<0.09)$, and treatment $\times$ sex $\times$ measure, $p<0.000 \mathrm{I})$, necessitating separation of values for males $(a, b, c)$ and females (d, e, $f$ ). ANOVA across regimens and measures appears at the top of each panel and, where a treatment $\times$ regimen interaction was found, lower-order tests for each regimen are shown at the bottom. Within each regimen, tests of significance for individual measures (asterisks) were carried out only where there was a treatment $\times$ measure interaction, and otherwise, only main treatment effects are presented. Iso = isoproterenol, Fsk = forskolin, Clon $=$ clonidine, Carb $=$ carbachol.

$(0.175 \pm 0.007$ in controls, $0.137 \pm 0.003$ across all three Dex regimens, $p<0.0001)$. Similar effects were obtained at the highest Dex dose $(0.8 \mathrm{mg} / \mathrm{kg}$, Figure $9 \mathrm{c})$, with overall increases in responses to direct $\mathrm{AC}$ stimulants and deficiencies in the relative response to input from $\beta \mathrm{ARs}$ $(p<0.0001$ for the $\beta \mathrm{AR} /$ forskolin ratio $)$ or $\mathrm{m}_{2} \mathrm{AChRs}$
( $p<0.05$ for the ratio of forskolin-stimulated activity with/ without carbachol).

Although females also exhibited significant cerebrocortical AC upregulation after Dex treatments, in general, they were less sensitive than males. At $0.05 \mathrm{mg} / \mathrm{kg}$, females showed increases in AC only with the PN7-9 regimen 
(Figure 9d). Within that group, $\beta$ ARs again showed specific uncoupling $(0.142 \pm 0.006$ for the isoproterenol/forskolin ratio in controls, $0.127 \pm 0.004$ in the Dex group, $p<0.05$ ), but there was no significant effect on the response ratios (forskolin-stimulated activity with/without agonist) for clonidine or carbachol. With an increase in the Dex dose to $0.2 \mathrm{mg} / \mathrm{kg}$, AC upregulation was still limited to the PN7-9 regimen (Figure 9e); there was about $10 \%$ uncoupling of the specific $\beta \mathrm{AR}$ response (control isoproterenol/forskolin ratio of $0.142 \pm 0.006 v s 0.129 \pm 0.002$ in the Dex group, $p<0.04$ ) At the highest Dex dose, there were slightly smaller effects and higher variability that occluded the ability to demonstrate statistical significance, although at the same time, the general pattern was statistically indistinguishable from the significant increases obtained at the lower doses (Figure 9f).

To characterize the greater cerebrocortical AC induction in males as compared to females, we contrasted the overall effect of Dex across all regimens, doses, and AC measures in the two sexes. The increase in males averaged $20 \%$, twice that seen in females $(p<0.0001)$. Furthermore, since controls displayed a significantly higher AC activity in females (Table 1), the effect of Dex effectively eliminated the normal sex difference. Whereas controls showed a main effect of sex across all AC measures $(p<0.008)$, the Dextreated animals did not display significant sex differences.

Compared to the cerebral cortex, effects of Dex treatment on AC in the hippocampus were much smaller. In males, the lowest Dex dose elicited small but significant AC upregulation with the GD17-19 regimen and similar effects were obtained (at the margin of significance) for the PN1-3 group (Figure 10a). However, with the PN7-9 regimen, there was no $\mathrm{AC}$ upregulation and in fact, deficits were obtained for basal AC and the response to isoproterenol. Across all three regimens, there was a significant reduction in the isoproterenol/forskolin response ratio $(p<0.04)$, signifying receptor uncoupling, although most of the effect reflected the actions in the group receiving the PN7-9 regimen. There were no corresponding changes in the relative responses to clonidine or carbachol (ie forskolinstimulated activity with/without agonist); however, as these agents did not reduce AC in control hippocampus (Table 1), a lack of effect of Dex is not meaningful. With the intermediate dose of Dex $(0.2 \mathrm{mg} / \mathrm{kg})$, there was a correspondingly greater overall upregulation of AC activity, which now included the group receiving the PN7-9 regimen (Figure 10b). Superimposed on this effect, $\beta$ AR responses again showed uncoupling, as evidenced by a reduction in the isoproterenol/forskolin response ratio from $0.190 \pm$ 0.005 in controls to $0.170 \pm 0.006$ across all three Dex regimens $(p<0.005)$. The response to the highest Dex dose $(0.8 \mathrm{mg} / \mathrm{kg}$, Figure $10 \mathrm{c})$ was once more nonmonotonic, with slightly less AC upregulation than that obtained at $0.2 \mathrm{mg} /$ $\mathrm{kg}$. The $\beta \mathrm{AR}-\mathrm{mediated}$ response showed the same characteristic reduction of the isoproterenol/forskolin response ratio $(p<0.002)$

Unlike the situation seen in the cerebral cortex, in the hippocampus the lowest Dex dose elicited equivalent or even greater AC upregulation in females as in males (Figure 10d). In addition, the PN7-9 did not elicit AC deficits in females whereas it did in males. Surprisingly, although, when the dose was raised to $0.2 \mathrm{mg} / \mathrm{kg}$, the response pattern in females then resembled that seen in males at the lowest dose (Figure 10e). This relationship was reinforced by the effects at $0.8 \mathrm{mg} / \mathrm{kg}$ (Figure 10f), where females displayed essentially the same effect that had been in males at $0.2 \mathrm{mg} /$ $\mathrm{kg}$. In keeping with this view, across all regimens, doses, and AC measures, the overall effect of Dex on AC was $15 \%$ less in females than in males (treatment $\times \operatorname{sex}, p<0.02$ ). However, as the sex difference in Dex effect was smaller for the hippocampus than the cerebral cortex, the slight difference in upregulation only partially offset the inherent sex differences in AC activity (Table 1), so that females still maintained significantly higher absolute AC activities in the hippocampus even in the Dex groups $(p<0.002)$.

Effects of Dex on AC responses in the striatum, like the hippocampus, were much smaller than those obtained in the cerebral cortex. In males given the $0.05 \mathrm{mg} / \mathrm{kg}$ of Dex, only a small degree of AC upregulation was evident, achieving significance only for $\mathrm{Mn}^{2+}$ (Figure 11a). Increasing the dose to $0.2 \mathrm{mg} / \mathrm{kg}$ (Figure $1 \mathrm{lb}$ ) had a correspondingly larger effect on AC in the group receiving the GD17-19 regimen, although the other two regimens remained at about the same small effect level as seen at the lower dose. As before, there was a smaller effect when the dose was increased to $0.8 \mathrm{mg} / \mathrm{kg}$ (Figure 11c). For the striatum, as in the hippocampus, females given $0.05 \mathrm{mg} / \mathrm{kg}$ of Dex showed an equivalent or even larger AC upregulation as compared to males (Figure 11d), a reduced effect at $0.2 \mathrm{mg} / \mathrm{kg}$ (Figure $11 \mathrm{e})$, but an enhanced effect at $0.8 \mathrm{mg} / \mathrm{kg}$ instead of the reduced effect seen in males (Figure 11f). Across all regimens, doses, and $\mathrm{AC}$ measures, females actually showed greater overall AC upregulation, averaging approximately half again as much as the effect in males (treatment $\times$ sex, $p<0.04)$. Uncoupling of the $\mathrm{G}_{\mathrm{s}}$-mediated response, assessed as the dopamine/forskolin ratio, was significant for males at $0.2 \mathrm{mg} / \mathrm{kg}(p<0.04)$ and $0.8 \mathrm{mg} / \mathrm{kg}(p<0.05)$ but not for females, nor did either sex show significant changes in the ability of clonidine or carbachol to inhibit forskolinstimulated AC.

Finally, for each of the regions, Dex did not elicit any significant changes in the preference for stimulatory responses to forskolin vs $\mathrm{Mn}^{2+}$ (ie no change in the forskolin/ $\mathrm{Mn}^{2+}$ activity ratio), so that the marked increase in overall AC activity most likely represented AC induction without a change in the isoform.

\section{Effects on Development of the Cerebellum}

As in the forebrain, there were few sex differences in indices of cerebellar cell number and size in control animals (Table 2). In keeping with the large proportion of cell bodies in the cerebellum, the DNA concentration was much higher than in forebrain regions and as expected, the development of neural projections was accompanied by a progressive increase in the ratios of total protein/DNA and membrane/ total protein. In association with the peak of neurogenesis in the postnatal period (Bell et al, 1986; Rodier, 1988), $\alpha_{2}$ ARs were overexpressed as compared to weanling or adult values.

Although postnatal treatment with high doses of Dex elicits cerebellar stunting (Bohn, 1984), with GD17-19 treatment we found only minor effects on indices of cell number and cell size with assessment on PN75 (Figure 12): no effect on DNA biomarkers or weight at $0.05 \mathrm{mg} / \mathrm{kg}$ and 
a Adenylyl Cyclase - Male Hippocampus - Dex $0.05 \mathrm{mg} / \mathrm{kg}$

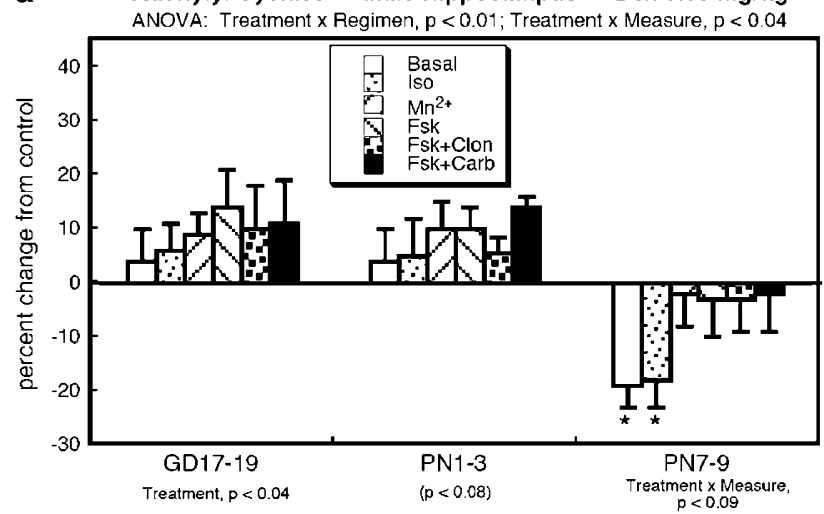

b Adenylyl Cyclase - Male Hippocampus - Dex $0.2 \mathrm{mg} / \mathrm{kg}$ ANOVA: Treatment, $p<0.005$; Treatment $x$ Neasure, $p<0.0009$ $\mathrm{Mn}^{2+}, \mathrm{p}<0.03 ;$ Fsk, $\mathrm{p}<0.002 ;$ Fsk+Clon, $\mathrm{p}<0.05 ;$ Fsk+Carb, $\mathrm{p}<0.01$

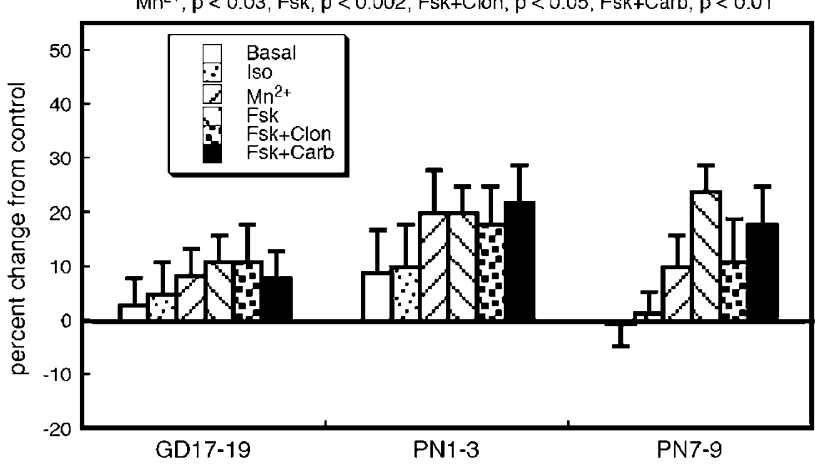

C Adenylyl Cyclase - Male Hippocampus - Dex $0.8 \mathrm{mg} / \mathrm{kg}$ ANOVA: Treatment $x$ Measure, $p<0.0002$ $\mathrm{Mn}^{2+}, \mathrm{p}<0.05 ;$ Fsk, $\mathrm{p}<0.04 ;$ Fsk+Clon, $\mathrm{p}<0.05 ;$ Fsk+Carb, $\mathrm{p}<0.04$

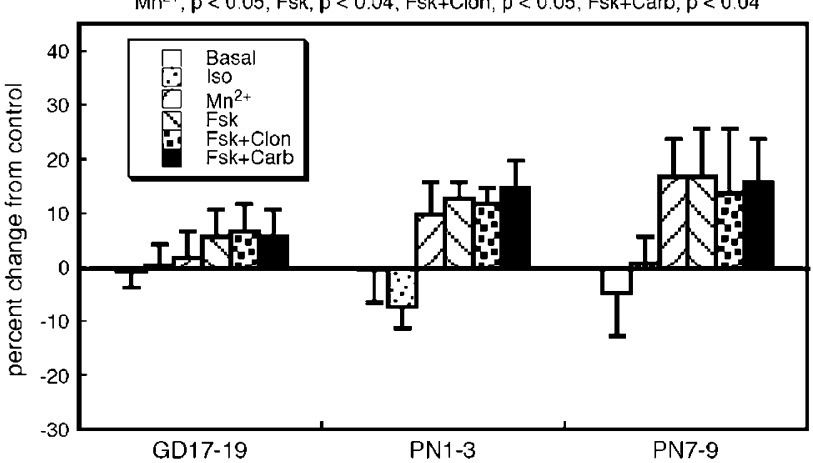

Adenylyl Cyclase - Female Hippocampus - Dex $0.05 \mathrm{mg} / \mathrm{kg}$ ANOVA: Treatment, $p<0.004$

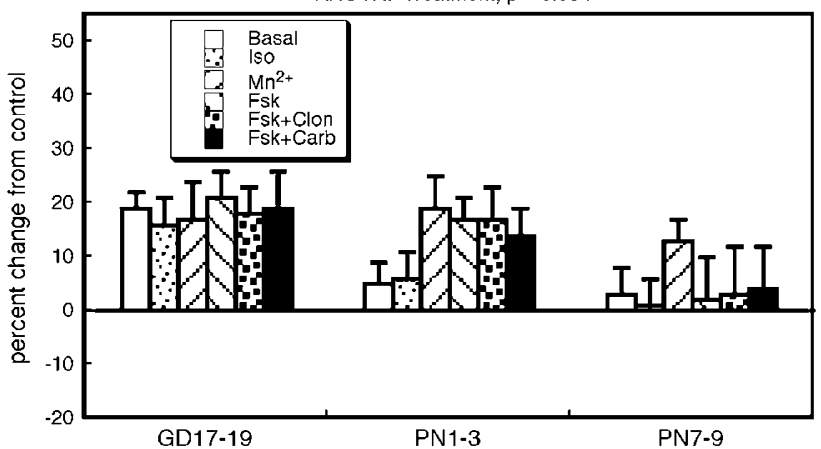

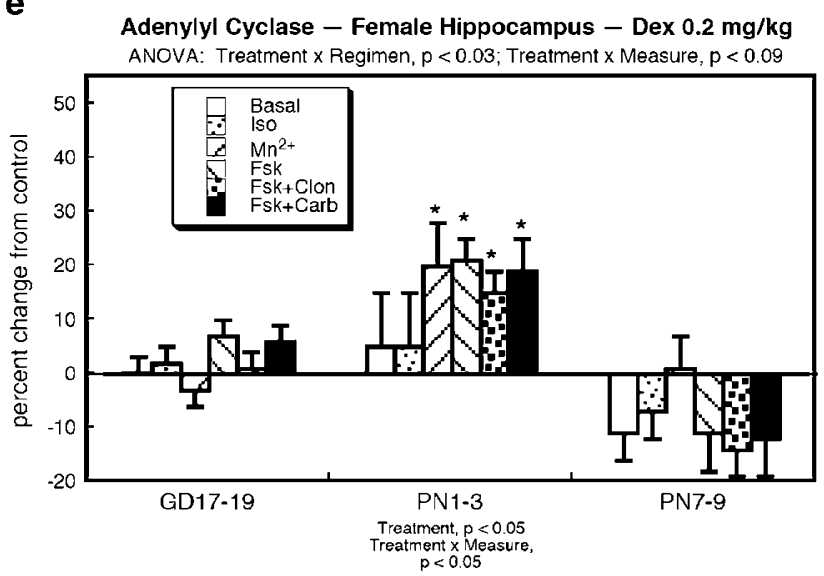

f Adenylyl Cyclase - Female Hippocampus - Dex $0.8 \mathrm{mg} / \mathbf{k g}$ ANOVA: Treatment, $\mathrm{p}<0.002$; Treatment $\mathrm{x}$ Regimen $\mathrm{x}$ Measure, $\mathrm{p}<0.009$

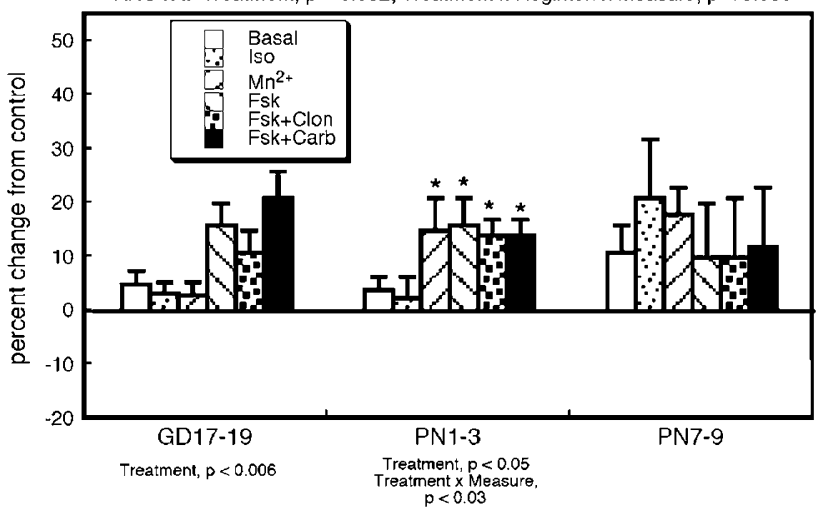

Figure 10 Effects of Dex regimens on hippocampal AC signaling, evaluated on PN75 and presented as the percent change from control values shown in Table I: treatment with (a, d) $0.05 \mathrm{mg} / \mathrm{kg}$, (b, e) $0.2 \mathrm{mg} / \mathrm{kg}$, and (c, f) $0.8 \mathrm{mg} / \mathrm{kg}$. Across all regimens, doses and AC measures, and both sexes, ANOVA identified a main treatment effect $(p<0.008)$ and interactions of treatment $\times$ regimen $(p<0.02)$, treatment $\times$ measure $(p<0.003)$, and treatment $\times$ sex $(p<0.02)$, necessitating separation of values for males $(a, b, c)$ and females $(d, e, f)$. ANOVA across regimens and measures appears at the top of each panel and, where a treatment $\times$ regimen interaction was found, lower-order tests for each regimen are shown at the bottom. Within each regimen, tests of significance for individual measures (asterisks) were carried out only where there was a treatment $\times$ measure interaction, and otherwise, only main treatment effects are presented. Iso $=$ isoproterenol, Fsk $=$ forskolin, Clon $=$ clonidine, Carb $=$ carbachol.

up to $5-10 \%$ decreases in DNA concentration and content at the highest dose $(0.8 \mathrm{mg} / \mathrm{kg})$. The decrease in DNA was associated with an increase in the total protein/DNA ratio, up to $20 \%$ at the highest Dex dose (data not shown). Given these relatively small effects, we then evaluated whether there were larger deficits earlier in development that were then offset during later stages.
Cerebellar growth deficits were apparent in the early postnatal period only at the highest Dex dose, with restoration of normal tissue weights by weaning (Figure 12a). In contrast, effects on the DNA concentration were robust even at $0.2 \mathrm{mg} / \mathrm{kg}$ and exceeded the growth impairment both in magnitude and duration, with $20 \%$ deficits still apparent by PN 23 (Figure 12b). Similarly, DNA content 
a

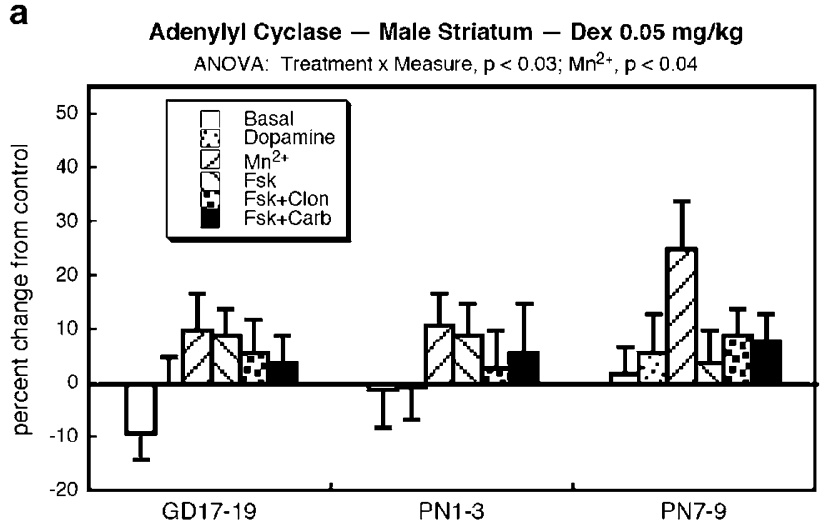

Adenylyl Cyclase - Male Striatum - Dex $0.2 \mathrm{mg} / \mathrm{kg}$
ANOVA: Treatment, $\mathrm{p}<0.007 ;$ Treatment $x$ Measure, $\mathrm{p}<0.02$ $\mathrm{Mn}^{2+}, \mathrm{p}<0.004 ;$ Fsk, $\mathrm{p}<0.02 ;$ Fsk+Clon, $\mathrm{p}<0.004 ;$ Fsk+Carb, $\mathrm{p}<0.002$

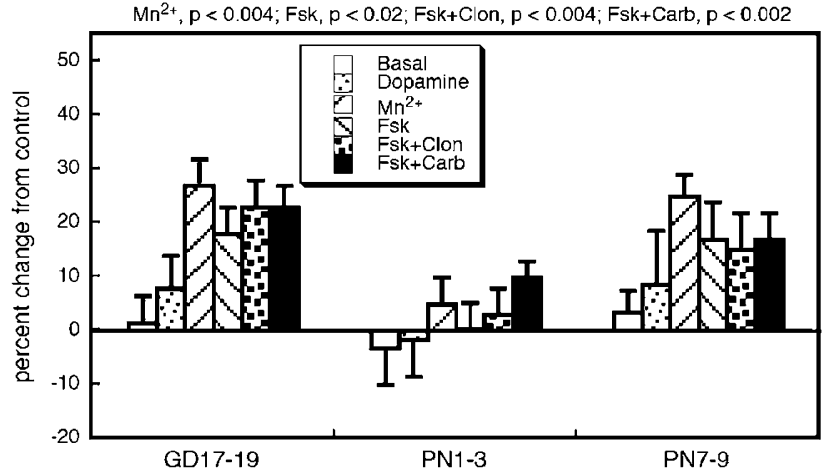

C

C Adenylyl Cyclase - Male Striatum - Dex $0.8 \mathrm{mg} / \mathrm{kg}$

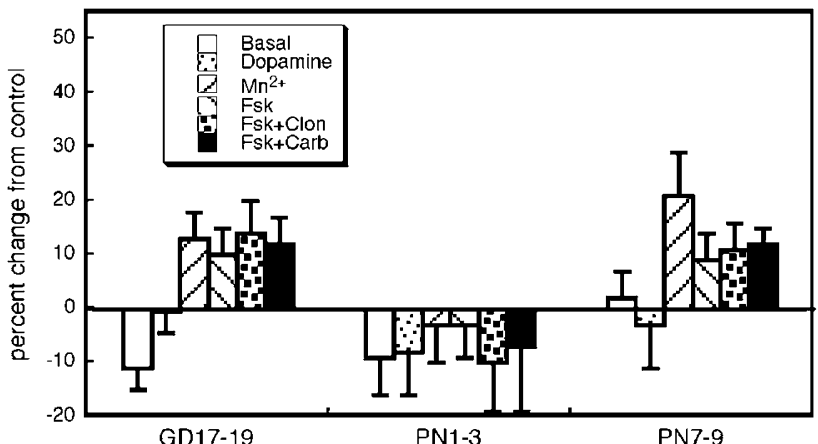

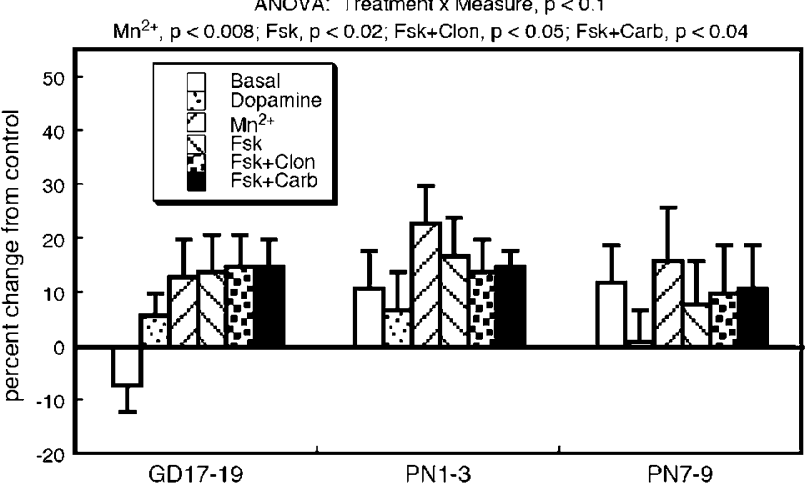

e

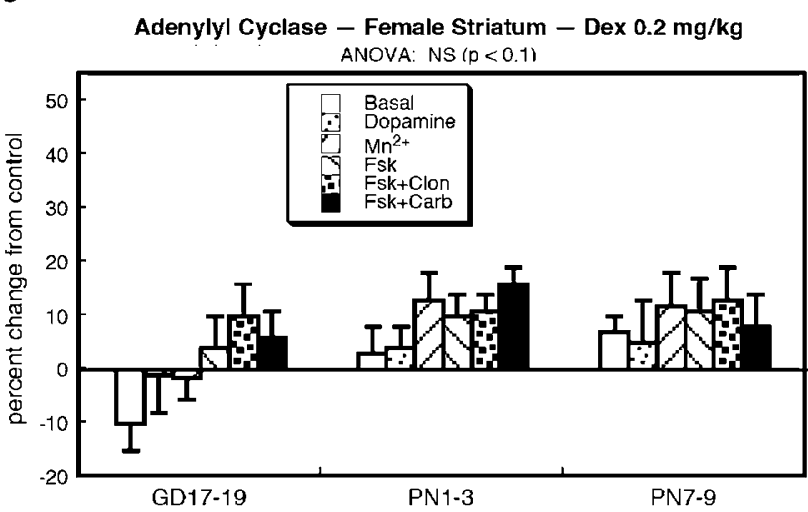

f

Adenylyl Cyclase - Female Striatum - Dex $0.8 \mathrm{mg} / \mathrm{kg}$ ANOVA: Treatment, $\mathrm{p}<0.003$

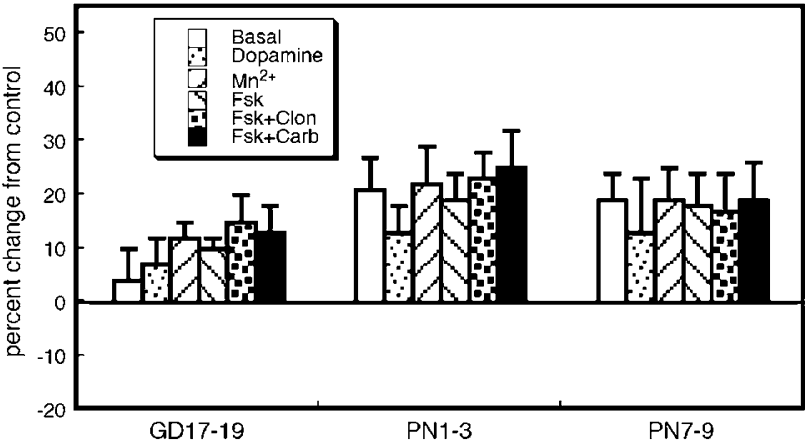

Figure I I Effects of Dex regimens on striatal AC signaling, evaluated on PN75 and presented as the percent change from control values shown in Table I: treatment with (a, d) $0.05 \mathrm{mg} / \mathrm{kg}$, (b, e) $0.2 \mathrm{mg} / \mathrm{kg}$, and (c, f) $0.8 \mathrm{mg} / \mathrm{kg}$. Across all regimens, doses and AC measures, and both sexes, ANOVA identified a main treatment effect $(p<0.02)$ and interactions of treatment $\times$ measure $(p<0.003)$ and treatment $\times$ sex $(p<0.05)$, necessitating separation of values for males $(a, b, c)$ and females ( $d, e, f)$. ANOVA across regimens and measures appears at the top of each panel. Lower-order tests for each regimen or for each measure within a given regimen were not evaluated because of the absence of treatment $\times$ regimen interactions. NS, not significant. Fsk $=$ forskolin, Clon = clonidine, Carb $=$ carbachol.

was reduced by $20-30 \%$ at 0.2 and $0.8 \mathrm{mg} / \mathrm{kg}$ Dex, with restoration occurring only in adolescence (Figure 12c). Dex also elicited major defects in membrane outgrowth, with $20-40 \%$ deficits in the membrane/total protein ratio at PN10, resolving by weaning (Figure 12d). Notably, for this index, even the lowest Dex dose, $0.05 \mathrm{mg} / \mathrm{kg}$, had a significant effect. Finally, assessment of $\alpha_{2} \mathrm{AR}$ binding indicated a major shift in the ontogenetic pattern, with large increases in receptor expression on PN10 followed by a rapid fall to slightly subnormal values, and essentially normal binding values in later stages after the end of neurogenesis (Figure 12e).

\section{DISCUSSION}

The key findings of this study are: (1) Dex administration produces lasting changes in forebrain regions, with a wide window of vulnerability extending throughout the entire period in which glucocorticoids are likely to be used in preterm infants; (2) adverse effects are elicited even at doses below those required for therapeutic actions in the prevention of respiratory distress syndrome; (3) brain development is targeted at multiple levels, extending from growth inhibition and neural cell loss, through alterations in synaptic activity and cell signaling; (4) indices of synaptic 
function are affected far more and at lower Dex doses than are anatomical indices of somatic growth and neural cell number and size; (5) raising the Dex dose to the point of permanent growth impairment reduces some of the synaptic effects, reflecting superimposition of nonspecific somatic effects on the specific actions directed toward synaptic development and function; (6) superimposed on all these results, there are specific regional targets for each type of effect; (7) there are marked sex differences in the effects of Dex on synaptic function, often with a net outcome that obtunds normal sex disparities; and (8) longitudinal evaluations are likely to reveal even more widespread neurodevelopmental deficits. Given the large scope of this report, all of these conclusions will be discussed in turn for each of the groupings of biomarkers.

\section{Indices of Growth, and Neural Cell Number and Size}

We encompassed Dex doses spanning typical therapeutic use $(0.2-0.8 \mathrm{mg} / \mathrm{kg})$ as well as a dose well below that required for preterm infants $(0.05 \mathrm{mg} / \mathrm{kg})$. All three doses elicited somatic growth impairment in the preweaning period, and although all displayed eventual restoration to near-normal values, there were persistent weight deficits in adulthood at the highest dose. Furthermore, in keeping with an earlier study (Kreider et al, 2005a), growth impairment displayed greater sensitivity with postnatal treatment. To some extent, the lower effect in animals receiving Dex on GD17-19 is likely be pharmacokinetic in origin; with that regimen, Dex is administered to the dam, enabling maternal metabolism to reduce the effective fetal exposure. On the other hand, the somewhat larger initial growth deficits seen with $\mathrm{PN} 1-3$ regimen as compared to the PN7-9 regimen still implies that there is actually a critical period for impairment of somatic growth, logically reflecting the period of most rapid weight gain. The adverse effects on weight gain in the fetus and in early neonatal stages are themselves likely to contribute to the long-term liabilities of glucocorticoid use, as postulated in the 'Barker Hypothesis,' which relates early growth retardation to subsequent elevated risk of cardiovascular and metabolic disorders (Barker, 2003). In fact, dexamethasone treatment similarly increases the incidence of these syndromes (Barrington, 2001; Seckl, 2001), despite the eventual recovery of body weight as seen here.

As is typical for growth reduction (Bell et al, 1987; Dodge et al, 1975), effects on brain regions weights were smaller, reflecting 'brain-sparing.' Nevertheless, as discussed below, effects on synaptic function were not really spared by Dex administration and indeed, indices of synaptic function were often as large in the group receiving prenatal Dex as in the postnatal treatment groups, unrelated to the degree of somatic growth effects. Furthermore, none of the effects on growth indices showed sex selectivity, whereas disparate effects on males and females were a hallmark for biomarkers for synaptic activity and signaling. Thus, growth suppression per se does not provide a mechanism for, or a predictor of, adverse effects on neural function.

In an earlier study (Kreider et al, 2005a), we examined Dex effects in the immediate post-treatment period and found marked deficits in neural cell numbers evoked by postnatal Dex regimens, along with a smaller degree of impairment of neural cell growth. The current results show that reduced cell numbers remain evident in adulthood, likely reflecting a permanent cell loss. These findings reinforce a primary effect of Dex on cell acquisition (Bohn, 1984), and because neurons are formed only during a discrete developmental period (Rodier, 1988), the initial reductions can never be made up completely. Our studies also indicate, albeit indirectly, that enhanced cell death is a likely contributor to the effects on cell number. The major phase of cerebrocortical neurogenesis is completed in the late gestational and early neonatal period in the rat (Rodier, 1988), yet for that region, we found the greatest long-term deficits in DNA content with the PN7-9 regimen and the least effect with the GD17-19 regimen. The issue of a critical period of vulnerability for cell acquisition was also addressed in the longitudinal study of the effects of the GD17-19 regimen on the cerebellum, a region in which neurogenesis peaks in the first two postnatal weeks (Bell et al, 1986; Rodier, 1988); because Dex exposure occurred in the phase prior to the termination of neurogenesis, nearly all of the gross deficits in cell number were eventually made up in this region.

In contrast to the primary effects of Dex on cell number, the effects on indices of cell size were less robust and consistent. Nevertheless, the cerebral cortex repeatedly stood out as a specific regional target with a critical exposure window for the PN7-9 regimen. At the highest dose, this region and regimen also showed an increase in the total protein/DNA ratio, indicative of an increase in cell size. In association with the larger deficit in DNA content and reduced membrane/total protein, this finding is consistent with perikaryal enlargement at the expense of cell numbers and neurite extension, findings that are characteristic for high, growth-stunting doses of Dex (Bohn, 1984). Our findings indicate that these, too, are changes that persist into adulthood.

Despite the targeting of specific regions or differential effects across the three different periods in which we administered Dex, the main points remain that there is a wide window of vulnerability of cell acquisition and growth to Dex administration, with significant, lasting changes obtained even at the lowest Dex dose. Nevertheless, these are overshadowed by the far greater effects on indices of synaptic activity and signaling, as discussed below.

\section{Cholinergic Presynaptic Indices}

In keeping with the targeting of synaptic function, we found much larger effects on $\mathrm{HC} 3$ binding, an index of cholinergic presynaptic activity, than on ChAT activity, a constitutive marker of cholinergic nerve terminals. Notably, Dex enhanced HC3 binding at all doses and with all regimens, indicating both a wide window of vulnerability and exquisite sensitivity, far exceeding that seen for growth impairment or indices of neural cell number or size. There were two notable features of the effects on HC3 binding that were not shared by any of the structural indices: specificity for males and selectivity for the hippocampus. In control rats, HC3 binding displayed a distinct sex difference, with significantly higher values in females as compared to males; accordingly, the augmented values in males given Dex treatment effectively eliminated the normal sex difference in HC3 binding. This, along with the selective effect on the 
hippocampus, is entirely in keeping with earlier behavioral findings, which similarly showed elimination of normal sex differences in hippocampus-related cognitive performance after gestational Dex treatment (Kreider et al, 2005b) or after maternal stress and its associated release of endogenous glucocorticoids (Bowman et al, 2004; Gerardin et al, 2005; Rieger et al, 2004). The present results thus provide a mechanistic underpinning for the behavioral effects. a

GD17-19 Dexamethasone Treatment Cerebellum Weight

ANOVA: Treatment, $p<0.0001$; Treatment $x$ Age, $p<0.0001$; Treatment $x$ Age $x$ Sex, $p<0.04$

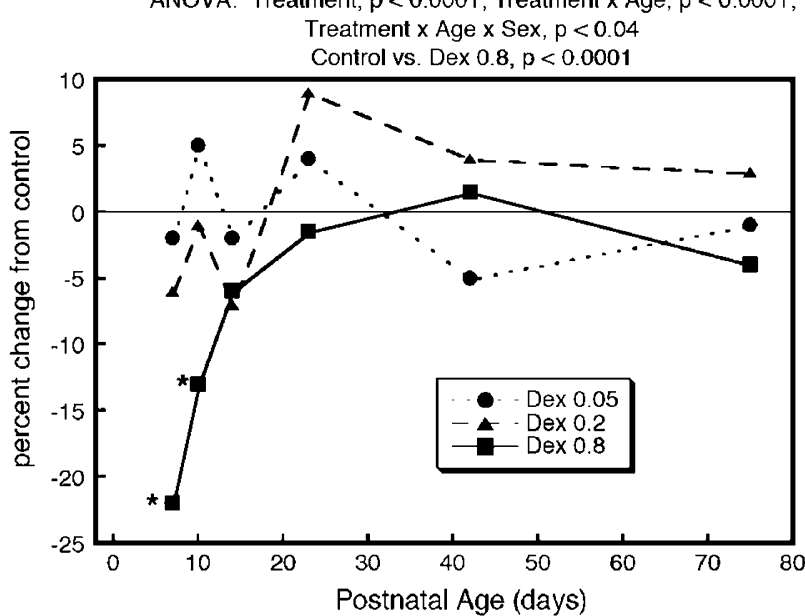

b

GD17-19 Dexamethasone Treatment Cerebellum DNA Concentration ANOVA: Treatment, $p<0.0001$; Treatment $x$ Age, $p<0.0001$ Control vs. Dex 0.2, p $<0.0001 ;$ Control vs. Dex 0.8, $p<0.0001$

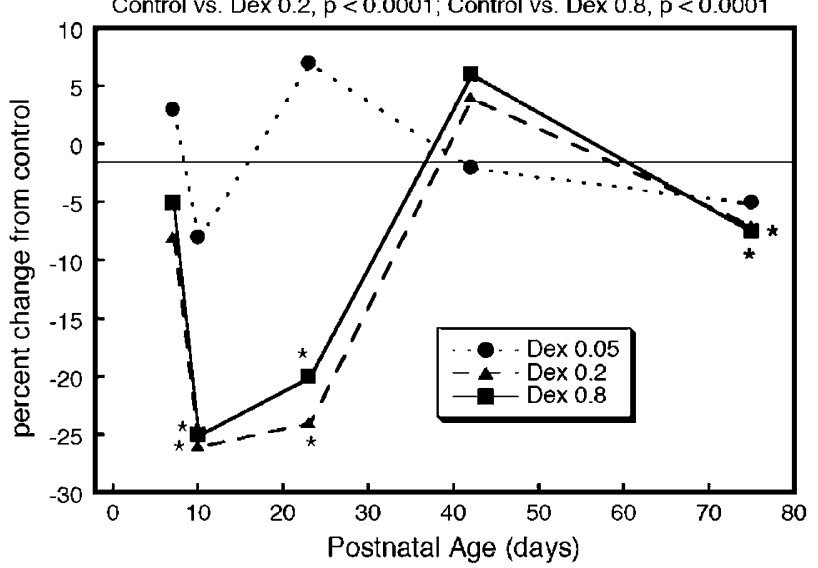

C

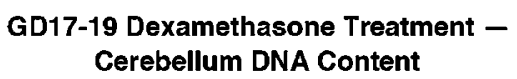

GD17-19 Dexamethasone Treatment Cerebellum DNA Content

ANOVA: Treatment, $p<0.0001$; Treatment $x$ Age, $p<0.0001$ Control vs. Dex 0.2, $p<0.0001$; Control vs. Dex 0.8, $p<0.0001$

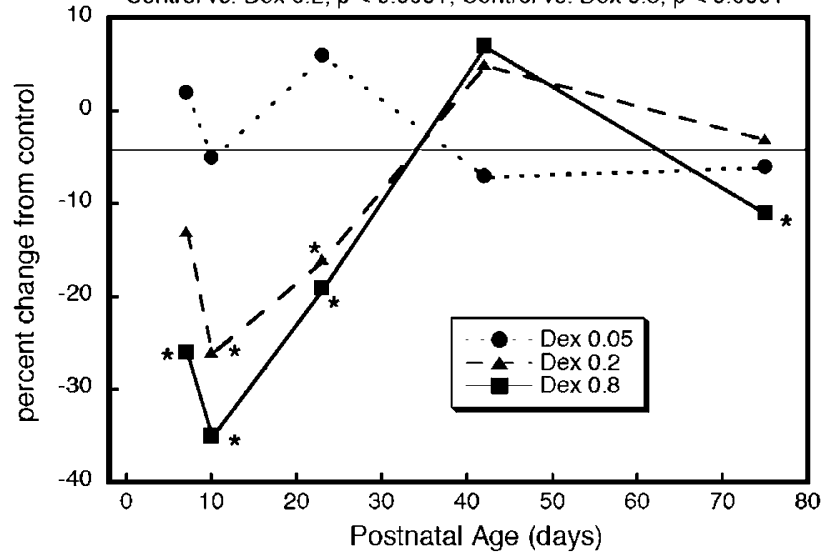

d

GD17-19 Dexamethasone Treatment Cerebellum Membrane/Total Protein ANOVA: Treatment, $p<0.0001$; Treatment $x$ Age, $p<0.0001$; Treatment $\times$ Age $\times$ Sex, $p<0.08$

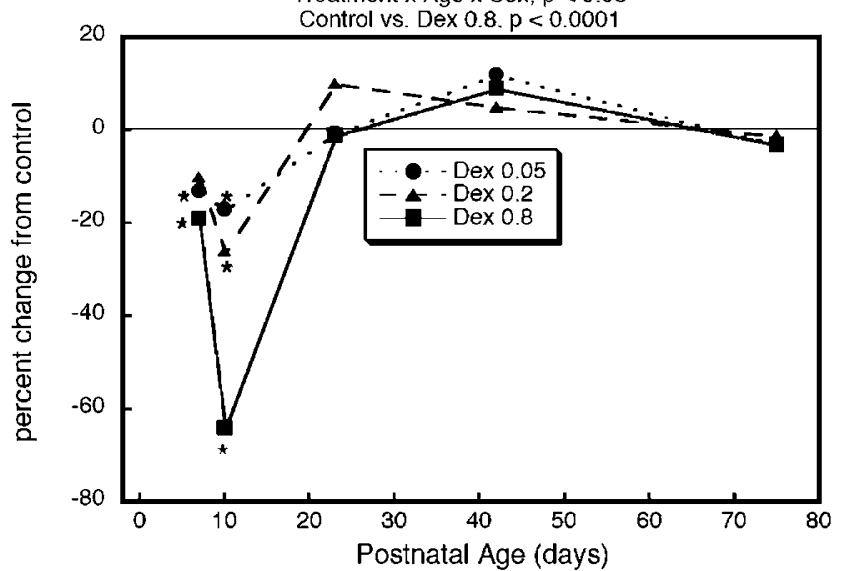

e GD17-19 Dexamethasone Treatment Cerebellum $\alpha_{2}$ AR Binding

ANOVA: Treatment $x$ Age, $p<0.0001$; Treatment $x$ Sex, $p<0.008$

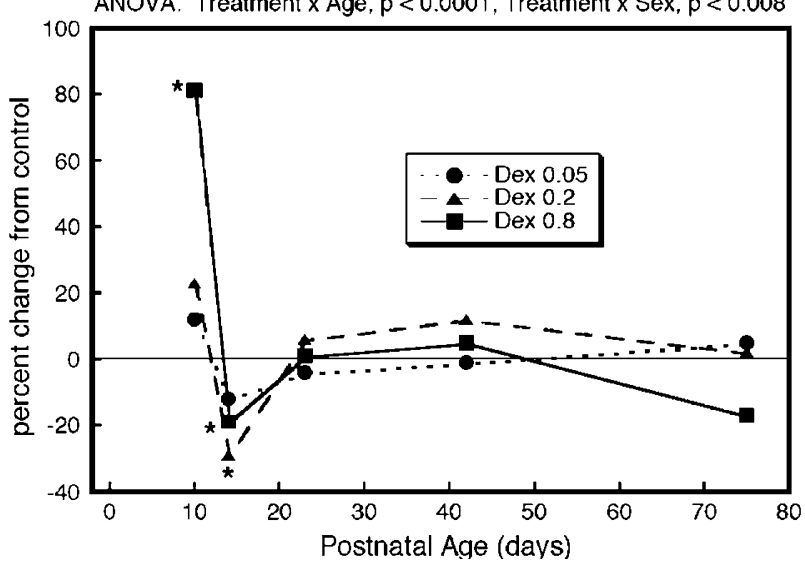


For ChAT activity, we also found a significant sex difference for Dex effects, albeit not to the same extent as for HC3 binding. The Dex group showed a partial, rather than a complete loss of the normal sex difference seen for ChAT, reflecting a small increase in activity for males and an overall decrease for females.

Both the effects on HC3 binding and ChAT activity showed a reduced effect of Dex as the dose was raised from 0.2 to $0.8 \mathrm{mg} / \mathrm{kg}$. This reinforces the idea that the effects on cholinergic activity are unrelated to growth impairment or neural cell loss and that, to the contrary, the adverse growth effects at the highest dose actually mask the primary actions of developmental exposure to Dex on the programming of cholinergic synaptic activity, conclusions in keeping with earlier demonstrations of biphasic effects of dexamethasone on development of neural activity (Slotkin et al, 1991a; Zahalka et al, 1993b). Finally, the lack of a relationship of growth indices to effects on cholinergic presynaptic biomarkers is reinforced by the different regional targets, with the cerebral cortex showing the greatest cell loss, whereas the hippocampus displayed the largest effects on HC3 binding.

\section{Neurotransmitter Receptor Binding}

In earlier work with these Dex regimens, we found immediate post-treatment upregulation of forebrain $\beta \mathrm{AR}$ expression, an effect that was limited to male rats treated on PN7-9 (Kreider et al, 2005a). With the present results, although we identified persistent effects on $\beta$ AR binding in adulthood, the effect was seen with both the PN1-3 and PN7-9 regimens, suggesting that the result in adulthood is not simply a longitudinal extension of the immediate neonatal actions, but rather represents a change in the long-term programming of $\beta \mathrm{AR}$ expression. As with $\mathrm{HC} 3$ binding, the effect of Dex on $\beta$ ARs was much greater in males than females but in this case, there was no underlying sex difference in control rats, so that the sex-selectivity for receptor binding created a male-female difference in the Dex groups where it did not ordinarily exist. Both the promotional effect of Dex on $\beta \mathrm{AR}$ expression and the sexselectivity were biphasic, with a diminished effect and loss of preferential actions on males when the dose was raised to $0.8 \mathrm{mg} / \mathrm{kg}$, above the threshold for permanent growth impairment. This relationship is reinforced by a shared regional specificity: the cerebral cortex, the region showing the greatest cell loss at the highest Dex dose, was also the one in which $\beta \mathrm{AR}$ upregulation was most prominent, and in which effects were diminished in the transition from 0.2 to $0.8 \mathrm{mg} / \mathrm{kg}$. As $\beta$ ARs are critical to the control of AC activity, the robust increase evoked by the intermediate dose of Dex will be important in the interpretation of effects on cell signaling, as discussed below.

Long-term receptor upregulation in Dex-treated animals was not limited to $\beta$ ARs. We also found significant increases in $\alpha_{2} \mathrm{AR}$ expression in the cerebral cortex, yet again with a biphasic characteristic in males, namely a diminished effect as the dose was raised from 0.2 to $0.8 \mathrm{mg} /$ $\mathrm{kg}$. However, the mechanisms underlying the effects on $\alpha_{2}$ ARs are clearly different from those for $\beta$ ARs, as the two receptors did not share a common critical Dex exposure window or pattern of sex-selectivity. For $\alpha_{2} \mathrm{ARs}$, males showed the greatest sensitivity with prenatal Dex treatment whereas females showed significant upregulation across all three regimens; indeed, there was more consistent upregulation for females than for males, whereas the opposite was true for $\beta$ ARs. The persistent effects of Dex on $\alpha_{2} A R$ expression clearly represent long-term programming, as in the immediate post-treatment period, Dex administration on GD17-19 decreases receptor binding (Kreider et al, 2005a), whereas by PN75, the same receptors were upregulated.

Finally, although Dex administration had an immediate post-treatment effect on $\mathrm{m}_{2} \mathrm{AChRs}$ (Kreider et al, 2005a), we did not observe any persistent effect on this receptor population in adulthood. The focused effects on adrenergic receptors may reflect a common origin in long-term hormonal effects of developmental Dex treatment. Both the $\alpha_{2} \mathrm{AR}$ and the $\beta \mathrm{AR}$ are directly regulated by hormonal input (Cornett et al, 1998; Davies and Lefkowitz, 1984; Dygalo et al, 2002), and it is therefore likely that the shift in hormone synthesis and metabolism that follows Dex treatment (Reznikov et al, 2004) contributes to the changes in receptor expression, in turn providing yet another factor that underlies the sex-selectivity of behavioral outcomes (Bowman et al, 2004; Kreider et al, 2005b).

\section{Cell Signaling}

By far, the most dramatic long-term effects of gestational or postnatal Dex administration were on all aspects of AC signaling, and here too, the actions were distinctly greater in males, directed toward the cerebral cortex, and more prominent with postnatal regimens, albeit that the alterations were still apparent in females, in the other regions, and with GD17-19 Dex treatment. For the most highly affected targets (male, cerebral cortex, PN1-3, and PN7-9 regimens), the principal finding was a marked upregulation of AC expression and an attendant increase in all measures involving direct $\mathrm{AC}$ stimulants $\left(\mathrm{Mn}^{2+}\right.$, forskolin, forskolin with other additions). Superimposed on this basic change, there were defects in the specific coupling of neurotrans-

Figure 12 Longitudinal assessment of the effects of GD 17-19 Dex treatment on cerebellar development, presented as the percent change from control values shown in Table 2: (a) cerebellum weight, (b) DNA concentration, (c) DNA content, (d) membrane/total protein ratio, and (e) $\alpha_{2}$ AR binding. Standard errors (not shown) were typically $1-2 \%$ for weight and $2-5 \%$ for the other measures. ANOVA across all doses and ages, and both sexes, appears at the top of each panel and asterisks denote individual values that differ from the corresponding control. Despite the treatment $\times$ age $\times$ sex interactions in panel (a), effects for males and females are shown combined because the treatment $x$ sex interactions were not maintained when values were separated by age. Similarly, the sex interactions in panels (d) and (e) represented significant differences at only one age point. For the membrane/total protein ratio on PN23, males showed an increase but females did not, and for $\alpha_{2}$ AR binding on PN42, one treatment group (Dex 0.2$)$ showed a slight increase in males and a slight decrease in females. Evaluations for the total protein/DNA ratio (not shown) indicated a significant treatment $\times$ age interaction $(p<0.004)$, reflecting a

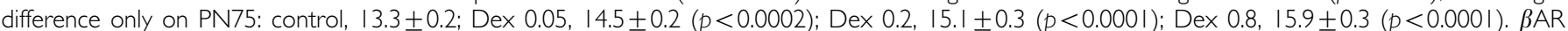
binding was assessed only on PN75 and was not significantly affected (not shown). 
mitter receptors to $\mathrm{AC}$, especially for $\beta \mathrm{ARs}$. Given the upregulation of both $\beta \mathrm{AR}$ and $\mathrm{AC}$ expression in the Dextreated groups, the response to isoproterenol would be expected to be highly supersensitive. Instead, isoproterenolstimulated AC activity was indistinguishable from that seen in controls and the specific isoproterenol response relative to total AC activity showed a significant deficit, suggesting a defect in $\beta \mathrm{AR}-\mathrm{AC}$ coupling via the stimulatory G-protein, $\mathrm{G}_{\mathrm{s}}$. Indeed, when we examined the ability of $\alpha_{2} \mathrm{ARs}$ or $\mathrm{m}_{2} \mathrm{AChRs}$ to inhibit AC, we similarly found a loss of response in the Dex groups, indicating universal impairment of excitatory $\left(G_{s}\right)$ or inhibitory $\left(G_{i}\right)$ G-protein signaling. Accordingly, there are two distinct, long-term effects of developmental Dex treatment on AC signaling, one involving upregulation of $\mathrm{AC}$ itself and the other comprising impairment of the ability of G-protein-coupled receptors to control AC activity. Given the widespread repertoire of neuronal and hormonal signals that operate through AC, both these classes of defects are likely to play major roles in neurobehavioral outcomes, with a general increase in cyclic AMP production accompanied by a loss of the ability of neurotransmitters and hormones to influence this second messenger. Just as discussed earlier, the fact that there was greater upregulation in males means that Dex treatment dissipates the normal sex difference in AC: whereas we found a significant sex difference (females $>$ males) for AC in controls, there was no sex difference for Dex-treated animals. As already discussed, this parallels the loss of sexually dimorphic behavioral performance (Bowman et al, 2004; Gerardin et al, 2005; Kreider et al, 2005b; Rieger et al, 2004).

The effects on cell signaling in the other two regions showed similarities to those seen in cerebral cortex but with a much smaller magnitude of effect. In the hippocampus, the selectivity for effects on males was diminished and accordingly, Dex only partially reversed the normal sex differences in AC. Nevertheless, specific uncoupling of $\beta$ ARs from the control of AC was still found. Again, the effects were biphasic with the PN7-9 regimen, the one displaying the greatest degree of somatic growth impairment and impact on general cell development: raising the dose to $0.8 \mathrm{mg} / \mathrm{kg}$ sometimes elicited a smaller induction of $\mathrm{AC}$ or even a reduction in activity. Finally, the striatum was different from the other two regions, with no inherent sex difference in AC in the controls and with females showing a greater effect of Dex. However, only the males showed uncoupling of striatal dopamine receptors from $\mathrm{G}_{\mathrm{s}}$ mediated AC stimulation, so that class of effect appears to be uniform across all three regions, and therefore distinct from the regionally selective induction of AC itself.

Our finding that the cerebral cortex is far more affected by developmental exposure to glucocorticoids, both in terms of cell signaling and for indices of neural cell development, is especially important. Previous work has focused largely on the hippocampus as the primary target for glucocorticoids (Coe et al, 2003; Roskoden et al, 2004; Takahashi, 1998; Tanapat et al, 1998), in recognition of its high concentration of glucocorticoid receptors in the fetus and neonate (Owen and Matthews, 2003). Instead, the present results indicate the need to spotlight the cerebral cortex, not only for neurochemical effects but also for alterations in structure and behavior.

\section{Longitudinal Assessment of Effects in Cerebellum}

We had two distinct reasons for contrasting the effects on cerebellar development with those seen in the three forebrain regions. First, high Dex doses given postnatally elicit cerebellar stunting to a greater extent than other regions (Bohn, 1984). Second, unlike the forebrain regions, the peak of neurogenesis occurs postnatally in the cerebellum (Bell et al, 1986; Rodier, 1988), so that comparative effects of Dex exposure in an early period (GD17-19) might enable us to reinforce the role of a critical phase for the outcome of Dex administration. As already discussed, despite gross early deficiencies in indices of cerebellar cell packing density, cell number, and cell size, most of the deficits were made up by adolescence. When we examined expression of $\alpha_{2}$ ARs, which are specifically associated with, and control neuronal cell proliferation (Kreider et al, 2004; Lidow and Rakic, 1994, 1995), we observed transient but massive upregulation preceding the 'catch-up' phase of cerebellar cell acquisition. In contrast, for the forebrain, the smaller initial deficits in cell development biomarkers (Kreider et al, 2005a) persisted at about the same level into adulthood and, in our earlier work (Kreider et al, 2005a), we found either no $\alpha_{2} \mathrm{AR}$ upregulation ( $\mathrm{PN} 1-3$ regimen) or a much smaller increase (PN7-9) than seen here for the cerebellum.

These findings suggest that the deficits in cell number and size evoked by Dex administration can be offset by neural plasticity, provided that the treatment terminates prior to the peak of neurogenesis. However, that is clearly not the case for many brain regions during the period in which Dex is most likely to be used in preterm infants, nor does such plasticity necessarily offset the long-term changes in synaptic function and signaling identified in the present work. Further, the results of the longitudinal evaluations in cerebellum indicate that the biochemical effects that are still present in adulthood may represent a residuum of much larger defects occurring earlier, during critical phases in which learning, memory, and other behavioral functions are consolidated. There is clearly a need for similar longitudinal evaluations of synaptic function and behavioral performance for other regions and for Dex administration spanning all the potential phases of neurodevelopment relevant to the use of glucocorticoids in preterm infants.

\section{Conclusion}

Dex administration during the phases of neurodevelopment in which glucocorticoids are used in preterm infants, elicits lasting changes in indices of neural cell numbers, but much greater alterations in synaptic activity and cell signaling throughout the forebrain. The fact that these changes occur at doses well below those used therapeutically means that adverse neurobehavioral outcomes may be an inescapable consequence. Further, the dissociation of effects on neuronal function from those on somatic growth or other indices of general development means that the latter do not provide an adequate predictor of long-term deficits. Similarly, given that the effects of Dex are distinctly sexselective, future evaluations must focus on differential effects in males $v s$ females, and particularly on the potential targeting of behaviors that are normally sexually dimorphic. 
Finally, the pronounced biphasic nature of the CNS effects seen at Dex doses that elicit permanent stunting means that functional or behavioral outcomes from high doses may differ substantially from those seen at lower doses, masking sex-selective effects in particular. Accordingly, many of the conclusions drawn from animal studies utilizing high dose treatments may not be applicable to Dex effects within the context of its actual use in preterm infants (Gilstrap et al, 1994) and may actually underestimate the ultimate impact on neurobehavioral function.

\section{ACKNOWLEDGEMENTS}

This study was supported by NIH HD09713.

\section{REFERENCES}

Aubert I, Cecyre D, Gauthier S, Quirion R (1996). Comparative ontogenic profile of cholinergic markers, including nicotinic and muscarinic receptors, in the rat brain. J Comp Neurol 369: 31-55.

Auman JT, Seidler FJ, Slotkin TA (2000). Neonatal chlorpyrifos exposure targets multiple proteins governing the hepatic adenylyl cyclase signaling cascade: implications for neurotoxicity. Dev Brain Res 121: 19-27.

Auman JT, Seidler FJ, Slotkin TA (2001a). Regulation of fetal cardiac and hepatic $\beta$-adrenoceptors and adenylyl cyclase signaling: terbutaline effects. Am J Physiol 281: R1079-R1089.

Auman JT, Seidler FJ, Tate CA, Slotkin TA (2001b). $\beta$-Adrenoceptor-mediated cell signaling in the neonatal heart and liver: responses to terbutaline. Am J Physiol 281: R1895-R1901.

Barker DJP (2003). The developmental origins of adult disease. Eur J Epidemiol 18: 733-736.

Barrington KJ (2001). The adverse neuro-developmental effects of postnatal steroids in the preterm infant: a systematic review of RCTs. BMC Pediatr 1: 1-9.

Bell JM, Whitmore WL, Queen KL, Orband-Miller L, Slotkin TA (1987). $\beta$-Biochemical determinants of growth sparing during neonatal nutritional deprivation or enhancement: ornithine decarboxylase, polyamines, and macromolecules in brain regions and heart. Pediatr Res 22: 599-604.

Bell JM, Whitmore WL, Slotkin TA (1986). Effects of $\alpha$ difluoromethylornithine, a specific irreversible inhibitor of ornithine decarboxylase, on nucleic acids and proteins in developing rat brain: critical perinatal periods for regional selectivity. Neuroscience 17: 399-407.

Bohn MC (1984). Glucocorticoid induced teratologies of the nervous system. In: Yanai J (ed). Neurobehavioral Teratology. Elsevier: Amsterdam. pp 365-387.

Bowman RE, MacLusky NJ, Sarmiento Y, Frankfurt M, Gordon M, Luine VN (2004). Sexually dimorphic effects of prenatal stress on cognition, hormonal responses, and central neurotransmitters. Endocrinology 145: 3778-3787.

Coe CL, Kramer M, Czeh B, Gould E, Reeves AJ, Kirschbaum C et al (2003). Prenatal stress diminishes neurogenesis in the dentate gyrus of juvenile rhesus monkeys. Biol Psychiat 54: $1025-1034$.

Cornett LE, Hiller FC, Jacobi SE, Cao WH, McGraw DW (1998). Identification of a glucocorticoid response element in the rat $\beta_{2}$-adrenergic receptor gene. Mol Pharmacol 54: 1016-1023.

Crowther CA, Harding J (2003). Repeat doses of prenatal corticosteroids for women at risk of preterm birth for preventing neonatal respiratory disease. Cochrane Database Syst Rev 1: CD003935.

Dammann O, Matthews SG (2001). Repeated antenatal glucocorticoid exposure and the developing brain. Pediatr Res 50: 563-564.
Davies AO, Lefkowitz RJ (1984). Regulation of $\beta$-adrenergic receptors by steroid hormones. Ann Rev Physiol 46: 119-130.

Dean F, Yu C, Lingas RI, Matthews SG (2001). Prenatal glucocorticoid modifies hypothalamo-pituitary-adrenal regulation in prepubertal guinea pigs. Neuroendocrinology 73: 194-202.

Dobbing J, Sands J (1979). Comparative aspects of the brain growth spurt. Early Hum Dev 3: 79-83.

Dodge PR, Prensky AL, Feigin RD (1975). Nutrition and the Developing Nervous System. C.V. Mosby: St Louis, MO. pp 1-538.

Dygalo NN, Kalinina TS, Sournina NY, Shishkina GT (2002). Effects of testosterone on $\alpha_{2 \mathrm{~A}}$-adrenergic receptor expression in the rat brain. Psychoneuroendocrinology 27: 585-592.

Felszeghy K, Bagdy G, Nyakas C (2000). Blunted pituitaryadrenocortical stress response in adult rats following neonatal dexamethasone treatment. J Neuroendocrinol 12: 1014-1021.

Fuxe K, Cintra A, Chadi G, Gustafsson JA, Agnati LF (1994). Central glucocorticoid receptors and neuronal plasticity. Meth Neurosci 22: 372-382.

Fuxe K, Diaz R, Cintra A, Bhatnagar M, Tinner B, Gustafsson JA et al (1996). On the role of glucocorticoid receptors in brain plasticity. Cell Mol Neurobiol 16: 239-258.

Garofolo MC, Seidler FJ, Auman JT, Slotkin TA (2002). $\beta$ Adrenergic modulation of muscarinic cholinergic receptor expression and function in the developing heart. Am J Physiol 282: R1356-R1363.

Gerardin DC, Pereira OC, Kempinas WG, Florio JC, Moreira EG, Bernardi MM (2005). Sexual behavior, neuroendocrine, and neurochemical aspects in male rats exposed prenatally to stress. Physiol Behav 84: 97-104.

Ghosh B, Wood CR, Held GA, Abbott BD, Lau C (2000). Glucocorticoid receptor regulation in the rat embryo: a potential site for developmental toxicity? Toxicol Appl Pharmacol 164: 221-229.

Gilad GM, Gilad VH, Eliyayev Y, Rabey JM (1998). Developmental regulation of the brain polyamine-stress-response. Int J Dev Neurosci 16: 271-278.

Gilstrap LC, Christensen R, Clewell WH, D'Alton ME, Davidson EC, Escobedo MB et al (1994). Effect of corticosteroids for fetal maturation on perinatal outcomes. $\mathrm{J} \mathrm{Am} \mathrm{Med} \mathrm{Assoc} \mathrm{273:}$ 413-418.

Gould E, Tanapat P, McEwen BS (1997). Activation of the type 2 adrenal steroid receptor can rescue granule cells from death during development. Dev Brain Res 101: 265-268.

Happe HK, Murrin LC (1992). High-affinity choline transport regulation by drug administration during postnatal development. J Neurochem 58: 2053-2059.

$\mathrm{Hu}$ ZT, Yuri K, Ichikawa T, Kawata M (1996). Exposure of postnatal rats to glucocorticoids suppresses the development of choline acetyltransferase-immunoreactive neurons: role of adrenal steroids in the development of forebrain cholinergic neurons. J Chem Neuroanat 10: 1-10.

Kamphuis PJ, Gardoni F, Kamal A, Croiset G, Bakker JM, Cattabeni $F$ et al (2003). Long-lasting effects of neonatal dexamethasone treatment on spatial learning and hippocampal synaptic plasticity: involvement of the NMDA receptor complex. FASEB J 17: 911-913.

Kamphuis PJGH, Croiset G, Bakker JM, van Bel F, van Ree JM, Wiegant VM (2004). Neonatal dexamethasone treatment affects social behaviour of rats in later life. Neuropharmacology 47: 461-474.

Klemm N, Kuhar MJ (1979). Post-mortem changes in high affinity choline uptake. J Neurochem 32: 1487-1494.

Kreider ML, Aldridge JE, Cousins MM, Oliver CA, Seidler FJ, Slotkin TA (2005a). Disruption of rat forebrain development by glucocorticoids: critical perinatal periods for effects on neural cell acquisition and on cell signaling cascades mediating 
noradrenergic and cholinergic neurotransmitter/neurotrophic responses. Neuropsychopharmacology (in press).

Kreider ML, Levin ED, Seidler FJ, Slotkin TA (2005b). Gestational dexamethasone treatment elicits sex-dependent alterations in locomotor activity, reward-based memory and hippocampal cholinergic function in adolescent and adult rats. Neuropsychopharmacology (in press).

Kreider ML, Seidler FJ, Cousins MM, Tate CA, Slotkin TA (2004). Transiently overexpressed $\alpha_{2}$-adrenoceptors and their control of DNA synthesis in the developing brain. Dev Brain Res 152: 233-239.

Labarca C, Piagen K (1980). A simple, rapid, and sensitive DNA assay procedure. Anal Biochem 102: 344-352.

Lau C, Seidler FJ, Cameron AM, Navarro HA, Bell JM, Bartolome J et al (1988). Nutritional influences on adrenal chromaffin cell development: comparison with central neurons. Pediatr Res 24: 583-587.

Lidow MS, Rakic P (1994). Unique profiles of the $\alpha 1-, \alpha 2-$, and $\beta$-adrenergic receptors in the developing cortical plate and transient embryonic zones of the rhesus monkey. J Neurosci 14: 4064-4078.

Lidow MS, Rakic P (1995). Neurotransmitter receptors in the proliferative zones of the developing primate occipital lobe. J Comp Neurol 360: 393-402.

Limbird LE, Macmillan ST (1981). Mn-uncoupling of the catecholamine sensitive adenylate cyclase system of rat reticulocytes. Biochim Biophys Acta 677: 408-416.

Maccari S, Darnaudery M, Morley-Fletcher S, Zuena AR, Cinque C, Van Reeth O (2003). Prenatal stress and long-term consequences: implications of glucocorticoid hormones. Neurosci Biobehav Rev 27: 119-127.

Matthews SG (2000). Antenatal glucocorticoids and programming of the developing CNS. Pediatr Res 47: 291-300.

Matthews SG, Owen D, Banjanin S, Andrews MH (2002). Glucocorticoids, hypothalamo-pituitary-adrenal (HPA) development, and life after birth. Endocr Res 28: 709-718.

McEwen BS (1992). Steroid hormones: effect on brain development and function. Horm Res 37: 1-10.

Meaney MJ, Diorio J, Francis D, Widdowson J, LaPlante P, Caldji C et al (1996). Early environmental regulation of forebrain glucocorticoid receptor gene expression: implications for adrenocortical responses to stress. Dev Neurosci 18: $49-72$.

Muneoka K, Mikuni M, Ogawa T, Kitera K, Kamei K, Takigawa M et al (1997). Prenatal dexamethasone exposure alters brain monoamine metabolism and adrenocortical response in rat offspring. Am J Physiol 42: R1669-R1675.

Navarro HA, Seidler FJ, Eylers JP, Baker FE, Dobbins SS, Lappi SE et al (1989). Effects of prenatal nicotine exposure on development of central and peripheral cholinergic neurotransmitter systems. Evidence for cholinergic trophic influences in developing brain. J Pharmacol Exp Ther 251: 894-900.

Nyirenda MJ, Welberg LA, Seckl JR (2001). Programming hyperglycaemia in the rat through prenatal exposure to glucocorticoids: fetal effect or maternal influence? J Endocrinol 170: 653-660.

Owen D, Matthews SG (2003). Glucocorticoids and sex-dependent development of brain glucocorticoid and mineralocorticoid receptors. Endocrinology 144: 2775-2784.

Qiao D, Seidler FJ, Abreu-Villaça Y, Tate CA, Cousins MM, Slotkin TA (2004). Chlorpyrifos exposure during neurulation: cholinergic synaptic dysfunction and cellular alterations in brain regions at adolescence and adulthood. Dev Brain Res 148: 43-52.

Qiao D, Seidler FJ, Tate CA, Cousins MM, Slotkin TA (2003). Fetal chlorpyrifos exposure: adverse effects on brain cell development and cholinergic biomarkers emerge postnatally and continue into adolescence and adulthood. Environ Health Persp 111: 536-544.
Reznikov AG, Nosenko ND, Tarasenko LV (2004). Early postnatal effects of prenatal exposure to glucocorticoids on testosterone metabolism and biogenic monoamines in discrete neuroendocrine regions of the rat brain. Comp Biochem Physiol C 138: 169-175.

Rieger M, Pirke KM, Buske-Kirschbaum A, Wurmser H, Papousek M, Hellhammer DH (2004). Influence of stress during pregnancy on HPA activity and neonatal behavior. Ann NY Acad Sci 1032: 228-230.

Rodier PM (1988). Structural-functional relationships in experimentally induced brain damage. Prog Brain Res 73: 335-348.

Roskoden T, Otten U, Schwegler H (2004). Early postnatal corticosterone administration regulates neurotrophins and their receptors in septum and hippocampus of the rat. Exp Brain Res 154: 183-191.

Seamon KB, Daly JW (1986). Forskolin: its biological and chemical properties. Adv Cyclic Nucleotide Protein Phosphoryl Res 20: $1-150$.

Seckl JR (2001). Glucocorticoid programming of the fetus: adult phenotypes and molecular mechanisms. Mol Cell Endocrinol 185: $61-71$.

Shi BT, Rabin SJ, Brandoli C, Mocchetti I (1998). Dexamethasone induces hypertrophy of developing medial septum cholinergic neurons: potential role of nerve growth factor. J Neurosci 18: 9326-9334.

Shinwell ES, Karplus M, Reich D, Weintraub Z, Blazer S, Bader D et al (2000). Early postnatal dexamethasone treatment and increased incidence of cerebral palsy. Arch Dis Child 83: F177-F181.

Simon JR, Atweh S, Kuhar MJ (1976). Sodium-dependent high affinity choline uptake: a regulatory step in the synthesis of acetylcholine. J Neurochem 26: 909-922.

Slotkin TA, Barnes G, Lau C, Seidler FJ, Trepanier P, Weigel SJ et al (1982). Development of polyamine and biogenic amine systems in brains and hearts of neonatal rats given dexamethasone: role of biochemical alterations in cellular maturation for producing deficits in ontogeny of neurotransmitter levels, uptake, storage and turnover. J Pharmacol Exp Ther 221: 686-693.

Slotkin TA, Lappi SE, Tayyeb MI, Seidler FJ (1991a). Dosedependent glucocorticoid effects on noradrenergic synaptogenesis in rat brain: ontogeny of $\left[{ }^{3} \mathrm{H}\right]$ desmethylimipramine binding sites after fetal exposure to dexamethasone. Res Comm Chem Pathol Pharmacol 73: 3-19.

Slotkin TA, McCook EC, Nemeroff CB, Seidler FJ (1991b). Species differences in $\alpha_{2}$-adrenergic regulation of platelet adenylate cyclase. Res Comm Chem Pathol Pharmacol 72: 259-271.

Slotkin TA, Persons D, Slepetis RJ, Taylor D, Bartolome J (1984). Control of nucleic acid and protein synthesis in developing brain, kidney, and heart of the neonatal rat: effects of $\alpha$ difluoromethylornithine, a specific, irreversible inhibitor of ornithine decarboxylase. Teratology 30: 211-224.

Slotkin TA, Seidler FJ, Crain BJ, Bell JM, Bissette G, Nemeroff CB (1990). Regulatory changes in presynaptic cholinergic function assessed in rapid autopsy material from patients with Alzheimer disease: implications for etiology and therapy. Proc Natl Acad Sci USA 87: 2452-2455.

Slotkin TA, Seidler FJ, Qiao D, Aldridge JE, Tate CA, Cousins MM et al (2005). Effects of prenatal nicotine exposure on primate brain development and attempted amelioration with supplemental choline or vitamin C: neurotransmitter receptors, cell signaling and cell development biomarkers in fetal brain regions of Rhesus monkeys. Neuropsychopharmacology 30: $129-144$

Smith PK, Krohn RI, Hermanson GT, Mallia AK, Gartner FH, Provenzano MD et al (1985). Measurement of protein using bicinchoninic acid. Anal Biochem 150: 76-85.

Snedecor GW, Cochran WG (1967). Statistical Methods. Iowa State University Press: Ames, Iowa. pp 593. 
Speirs HJ, Seckl JR, Brown RW (2004). Ontogeny of glucocorticoid receptor and $11 \beta$-hydroxysteroid dehydrogenase type- 1 gene expression identifies potential critical periods of glucocorticoid susceptibility during development. J Endocrinol 181: 105-116.

Takahashi LK (1998). Prenatal stress: consequences of glucocorticoids on hippocampal development and function. Int $J$ Dev Neurosci 16: 199-207.

Tanapat P, Galea LAM, Gould E (1998). Stress inhibits the proliferation of granule cell precursors in the developing dentate gyrus. Intl J Dev Neurosci 16: 235-239.

Trauth JA, Seidler FJ, Slotkin TA (2000). An animal model of adolescent nicotine exposure: effects on gene expression and macromolecular constituents in rat brain regions. Brain Res 867: 29-39.

Trautman PD, Meyer-Bahlburg HFL, Postelnek J, New MI (1995). Effects of early prenatal dexamethasone on the cognitive and behavioral development of young children: results of a pilot study. Psychoneuroendocrinology 20: 439-449.

Vickroy T, Roeske W, Yamamura H (1984). Sodium-dependent high-affinity binding of $\left[{ }^{3} \mathrm{H}\right]$ hemicholinium-3 in the rat brain: a potentially selective marker for presynaptic cholinergic sites. Life Sci 35: 2335-2343.

Weinstock M (2001). Alterations induced by gestational stress in brain morphology and behaviour of the offspring. Prog Neurobiol 65: 427-451.

Welberg LAM, Seckl JR (2001). Prenatal stress, glucocorticoids and the programming of the brain. J Neuroendocrinol 13: 113-128.

Winick M, Noble A (1965). Quantitative changes in DNA, RNA and protein during prenatal and postnatal growth in the rat. Dev Biol 12: $451-466$.
Yeh TF, Lin YJ, Lin HC, Huang CC, Hsieh WS, Lin CH et al (2004). Outcomes at school age after postnatal dexamethasone therapy for lung disease of prematurity. N Engl J Med 350: 1304-1313.

Zahalka EA, Seidler FJ, Lappi SE, Yanai J, Slotkin TA (1993a). Differential development of cholinergic nerve terminal markers in rat brain regions: implications for nerve terminal density, impulse activity and specific gene expression. Brain Res 601: 221-229.

Zahalka EA, Seidler FJ, Lappi SE, McCook EC, Yanai J, Slotkin TA (1992). Deficits in development of central cholinergic pathways caused by fetal nicotine exposure: differential effects on choline acetyltransferase activity and $\left[{ }^{3} \mathrm{H}\right]$ hemicholinium-3 binding. Neurotoxicol Teratol 14: 375-382.

Zahalka EA, Seidler FJ, Slotkin TA (1993b). Dexamethasone treatment in utero enhances neonatal cholinergic nerve terminal development in rat brain. Res Comm Chem Pathol Pharmacol 81: 191-198.

Zeiders JL, Seidler FJ, Iaccarino G, Koch WJ, Slotkin TA (1999a). Ontogeny of cardiac $\beta$-adrenoceptor desensitization mechanisms: agonist treatment enhances receptor/G-protein transduction rather than eliciting uncoupling. J Mol Cell Cardiol 31: 413-423.

Zeiders JL, Seidler FJ, Slotkin TA (1997). Ontogeny of regulatory mechanisms for $\beta$-adrenoceptor control of rat cardiac adenylyl cyclase: targeting of G-proteins and the cyclase catalytic subunit. J Mol Cell Cardiol 29: 603-615.

Zeiders JL, Seidler FJ, Slotkin TA (1999b). Agonist-induced sensitization of $\beta$-adrenoceptor signaling in neonatal rat heart: expression and catalytic activity of adenylyl cyclase. J Pharmacol Exp Ther 291: 503-510. 